\title{
The allosteric modulation of complement C5 by knob domain peptides
}

\author{
Alex Macpherson ${ }^{1,2 \star}$, Maisem Laabei ${ }^{2}$, Zainab Ahdash ${ }^{1}$, Melissa A Graewert ${ }^{3}$, \\ James R Birtley ${ }^{1}$, Monika-Sarah ED Schulze ${ }^{1}$, Susan Crennell ${ }^{2}$, Sarah A Robinson ${ }^{4}$, \\ Ben Holmes ${ }^{1}$, Vladas Oleinikovas ${ }^{1}$, Per H Nilsson ${ }^{1,5,6}$, James Snowden ${ }^{1}$, \\ Victoria Ellis ${ }^{1}$, Tom Eirik Mollnes ${ }^{6,7,8}$, Charlotte M Deane ${ }^{4}$, Dmitri Svergun ${ }^{3}$, \\ Alastair DG Lawson ${ }^{1}$, Jean MH van den Elsen ${ }^{2,9 *}$
}

${ }^{1}$ UCB, Slough, United Kingdom; ${ }^{2}$ Department of Biology and Biochemistry, University of Bath, Bath, United Kingdom; ${ }^{3}$ European Molecular Biology Laboratory, Hamburg Unit, Hamburg, Germany; ${ }^{4}$ Department of Statistics, University of Oxford, Oxford, United Kingdom; ${ }^{5}$ Department of Chemistry and Biomedicine, Linnaeus University, Kalmar, Sweden; 'Department of Immunology, Oslo University Hospital, University of Oslo, Oslo, Norway; ${ }^{7}$ Research Laboratory, Bodø Hospital, K.G. Jebsen TREC, University of Tromsø, Tromsø, Norway; ${ }^{8}$ Centre of Molecular Inflammation Research, Norwegian University of Science and Technology, Trondheim, Norway; ${ }^{9}$ Centre for Therapeutic Innovation, University of Bath, Bath, United Kingdom

*For correspondence:

Alex.MacPherson@ucb.com (AM); bssjmhve@bath.ac.uk (JMHE)

Competing interest: See page 22

Funding: See page 22

Received: 29 September 2020 Accepted: 11 February 2021 Published: 11 February 2021

Reviewing editor: John Kuriyan, University of California, Berkeley, United States

(c) Copyright Macpherson et al. This article is distributed under the terms of the Creative Commons Attribution License, which permits unrestricted use and redistribution provided that the original author and source are credited.

\begin{abstract}
Bovines have evolved a subset of antibodies with ultra-long heavy chain complementarity determining regions that harbour cysteine-rich knob domains. To produce highaffinity peptides, we previously isolated autonomous 3-6 kDa knob domains from bovine antibodies. Here, we show that binding of four knob domain peptides elicits a range of effects on the clinically validated drug target complement $\mathrm{C} 5$. Allosteric mechanisms predominated, with one peptide selectively inhibiting $\mathrm{C} 5$ cleavage by the alternative pathway $\mathrm{C} 5$ convertase, revealing a targetable mechanistic difference between the classical and alternative pathway C5 convertases. Taking a hybrid biophysical approach, we present C5-knob domain co-crystal structures and, by solution methods, observed allosteric effects propagating $>50 \AA$ from the binding sites. This study expands the therapeutic scope of $\mathrm{C} 5$, presents new inhibitors, and introduces knob domains as new, low molecular weight antibody fragments, with therapeutic potential.
\end{abstract}

\section{Introduction}

By the end of 2019, over 60 peptide drugs have received regulatory approval, with an estimated 400 more in active development globally (Lau and Dunn, 2018; Lee et al., 2019). As a potential route to discover therapeutic peptides, we previously reported a method for deriving peptides from the ultra-long heavy chain complementarity determining region 3 (ul-CDRH3), which are unique to a subset of bovine antibodies (Macpherson et alo, 2020). We have shown that knob domains, a cysteine-rich mini-domain common to all ul-CDRH3, can bind antigen autonomously when removed from the antibody scaffold (Macpherson et alo, 2020). This allows peptide affinity maturation to be performed in vivo, harnessing the cow's immune system to produce peptides with complex stabilising networks of disulphide bonds.

For the discovery of knob domain peptides, immunisation of cattle is followed by cell sorting of B-cells using fluorescently labelled antigen. A library of antigen-specific CDRH3 sequences is created by performing a reverse transcription polymerase chain reaction (RT PCR) on the B-cell lysate, 
eLife digest Antibodies are proteins produced by the immune system that can selectively bind to other molecules and modify their behaviour. Cows are highly equipped at fighting-off diseasecausing microbes due to the unique shape of some of their antibodies. Unlike other jawed vertebrates, cows' antibodies contain an ultra-long loop region that contains a 'knob domain' which sticks out from the rest of the antibody. Recent research has shown that when detached, the knob domain behaves like an antibody fragment, and can independently bind to a range of different proteins.

Antibody fragments are commonly developed in the laboratory to target proteins associated with certain diseases, such as arthritis and cancer. But it was unclear whether the knob domains from cows' antibodies could also have therapeutic potential. To investigate this, Macpherson et al. studied how knob domains attach to complement $\mathrm{C} 5$, a protein in the inflammatory pathway which is a drug target for various diseases, including severe COVID-19.

The experiments identified various knob domains that bind to complement C5 and inhibits its activity by altering its structure or movement. Further tests studying the structure of these interactions, led to the discovery of a common mechanism by which inhibitors can modify the behaviour of this inflammatory protein.

Complement $\mathrm{C} 5$ is involved in numerous molecular pathways in the immune system, which means many of the drugs developed to inhibit its activity can also leave patients vulnerable to infection. However, one of the knob domains identified by Macpherson et al. was found to reduce the activity of complement $\mathrm{C} 5$ in some pathways, whilst leaving other pathways intact. This could potentially reduce the risk of bacterial infections which sometimes arise following treatment with these types of inhibitors.

These findings highlight a new approach for developing drug inhibitors for complement C5. Furthermore, the ability of knob domains to bind to multiple sites of complement C5 suggests that this fragment could be used to target proteins associated with other diseases.

followed by a PCR using primers specific to the conserved framework regions which flank CDRH3 (Macpherson et al., 2020). Upon sequencing, ul-CDRH3s are immediately evident and the knob domains can be expressed recombinantly as cleavable fusion proteins (Macpherson et alo, 2020).

This method for the discovery of knob domain peptides was established using complement component C5, and we reported peptides which bound C5 with affinities in the pM-low nM range (Macpherson et al., 2020). Herein, we use these novel peptides to probe the structural and functional aspects of $\mathrm{C} 5$ activation.

C5 is the éminence grise of the complement cascade's druggable proteins, and the target of effective therapies for diseases with pathogenic complement dysregulation, of which paroxysmal nocturnal haemoglobinuria (Rother et al., 2007) and atypical haemolytic uraemic syndrome (Nürnberger et al., 2009) are notable examples. Six monoclonal antibodies targeting C5 have reached, or are entering, clinical trials, closely followed by C5-targeting immune evasion molecules (Romay-Penabad et alo, 2014), aptamers (Biesecker et alo, 1999), cyclic peptides (Ricardo et al., 2014), interfering RNA (Borodovsky et al., 2014), and small molecules (Jendza et al., 2019). Currently, C5 inhibitors are being trialled for the treatment of acute respiratory distress syndrome arising from severe acute respiratory syndrome coronavirus 2 (SARSCoV-2) infection (Smith et al., 2020; Wilkinson et al., 2020; Zelek et al., 2020) and for the neuromuscular disease myasthenia gravis (Albazli et al., 2020).

$\mathrm{C} 5$ is the principal effector of the terminal portion of the complement cascade. At high local C3b concentrations, arising from activation of either or both of the classical (CP) and mannose binding lectin (LP) pathways, aided by the amplificatory alternative pathway (AP), C5 is cleaved into two moieties with distinct biological functions. Cleavage is performed by two convertases: $\mathrm{C} 4 \mathrm{bC} 2 \mathrm{aC} 3 \mathrm{~b}$, formed in response to CP or LP activation (Takata et alo, 1987) (henceforth the CP C5 convertase), and $\mathrm{C} 3 \mathrm{bBbC} 3 \mathrm{~b}$, formed in response to AP activation (DiScipio, 1981) (henceforth the AP C5 convertase). Although the constitutive components of the $\mathrm{C} 5$ convertases differ, they are thought to be 
mechanistically identical. Once cleaved, the C5a fragment is the most proinflammatory anaphylatoxin derived from the complement cascade. When signalling through C5aR1 and C5aR2, C5a is a strong chemoattractant recruiting neutrophils, eosinophils, monocytes, and T lymphocytes to sites of complement activation, whereupon it activates phagocytic cells, prompting degranulation. C5b, meanwhile, interacts with C6, recruiting C7-C9 to form the terminal C5b-9 complement complex or TCC (Lachmann and Thompson, 1970). Once inserted into a cell membrane, the TCC is referred to as the membrane attack complex (MAC), a membrane-spanning pore which can lyse sensitive cells (Götze and Muiller-Eberhard, 1970).

Aspects of the structural biology of $\mathrm{C} 5$ are well understood due to a crystal structure of the apo form (Fredslund et al., 2008) and a number of co-crystal structures of C5 with various modulators. By virtue of its constitutive role in the terminal pathway, C5 is a recurrent target for immune evasion molecules and structures have been determined of C5 in complex with an inhibitory molecule derived from Staphylococcus aureus, SSL-7 (Laursen et al., 2010), as well as several structurally distinct examples from ticks: OmCl (Jore et al., 2016), $\mathrm{RaCl}$ (Jore et al., 2016), and CirpT (Reichhardt et al., 2020). Additionally, the structures of C5 with the inhibitory monoclonal antibody (mAb) eculizumab (Schatz-Jakobsen et al., 2016), of C5 with a small molecule inhibitor (Jendza et al., 2019), and of C5 with the complement-depleting agent cobra venom factor (CVF) (Laursen et al., 2011) have all been determined.

Here, we probe C5 with knob domain peptides and explore the molecular processes which underpin allosteric modulation of this important drug target. This study is the first to investigate the molecular mechanisms and pharmacology of this recently isolated class of peptide.

\section{Results}

\section{Bovine knob domain peptides as potential C5 inhibitors}

We have previously shown that antigen-specific, disulphide-rich knob domain peptides derived from bovine antibodies have great potential for therapeutic utility. Using this approach, we obtained four knob domain peptides: K8, K57, K92, and K149, which we have shown to display tight binding to human C5. Previously we reported equilibrium dissociation constants of $17.8 \mathrm{nM}$ for K8, $1.4 \mathrm{nM}$ for K57, <0.6 nM for K92, and 15.5 nM for K149 (Macpherson et al., 2020).

\section{Functional characterisation of anti-C5 bovine knob domain peptides}

For functional characterisation of the peptides, we performed complement assays for CP and AP activation in human serum, assessing C5b neo-epitope formation and C5a release (schematically presented in Figure 1A, B), in combination with orthogonal ELISAs, measuring C3b and C9 deposition. Here, we show that $\mathrm{K} 57$ was a potent and fully efficacious inhibitor of C5 activation, preventing release of $\mathrm{C} 5 \mathrm{a}$, and deposition of $\mathrm{C} 5 \mathrm{~b}$ and $\mathrm{C} 9$. As expected, there was no effect on $\mathrm{C} 3 \mathrm{~b}$, which is upstream of C5 (Figure 1C, D). In contrast, K149 was a high-affinity silent binder with no discernible effect on $\mathrm{C} 5 \mathrm{a}$ release, formation of $\mathrm{C} 5 \mathrm{~b}$ neo-epitope or $\mathrm{C} 9$ deposition, even at peptide concentrations in excess of $100 \times K_{D}$ (see Supplementary file 1 Section 1).

K8 and K92 exerted more nuanced allosteric effects on C5 (Figure 1C, D). By ELISA, K92 partially prevented $C 5$ activation by the AP, but, intriguingly, no effect was observed in $C P$ assays, suggesting $\mathrm{K} 92$ selectively inhibits C5 activation by the AP C5 convertase, but not the CP C5 convertase. Partial antagonists, where the degree of inhibition for the asymptotic concentrations of a doseresponse curve $\left(E_{\max }\right)$ is below $100 \%$, are an impossible mode of pharmacology for orthosteric antagonists (Klein et al., 2013), and we therefore propose that K92 operates by a non-steric mechanism. K8 was also demonstrably allosteric, partially inhibiting both the AP and CP in ELISA experiments. For $\mathrm{K} 8$ and $\mathrm{K} 92$, no effect on $\mathrm{C} 3 \mathrm{~b}$ deposition was detected.

When tested in CP and AP haemolysis assays (Figure 1E, F), K57 was a potent and fully efficacious inhibitor of complement-mediated cell lysis. Consistent with the ELISA data, K92 was active solely in the AP-driven haemolysis assay, achieving $E_{\max }$ values of $30-40 \%$; while $\mathrm{K} 8$ was efficacious in the CP assay but did not show activity in the AP assay below $10 \mu \mathrm{M}$, potentially a consequence of the increased serum concentration and stringency of the haemolysis endpoint. 


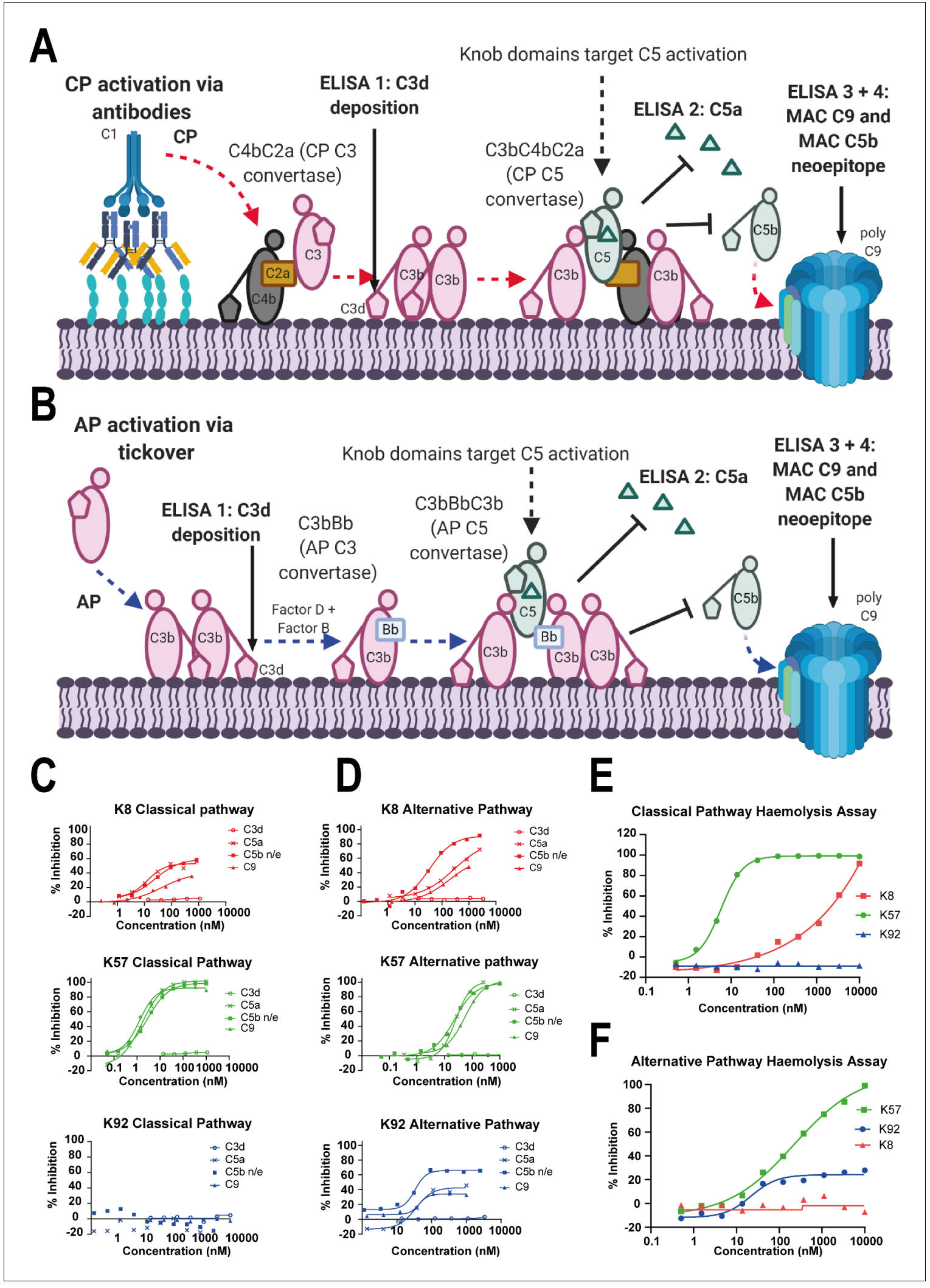

Figure 1. Functional modulation of $\mathrm{C} 5$ via knob domain peptides. (A) shows an abridged schematic for classical pathway (CP) activation. Following activation of C1q via antibody Fc, C4 and C2 are cleaved and form C4bC2a (the CP C3 convertase) which cleaves C3 into C3a (not shown) and C3b. At high $\mathrm{C} 3 \mathrm{~b}$ concentrations, $\mathrm{C} 4 \mathrm{bC2} \mathrm{aC} 3 \mathrm{~b}$ (the CP C3 convertase) forms and cleaves $\mathrm{C} 5$ into $\mathrm{C} 5 \mathrm{a}$ and $\mathrm{C} 5 \mathrm{~b}$. C5b associates with $\mathrm{C} 6$ and forms the membrane attack complex (MAC) with C7, C8, and multiple copies of C9. (B) shows an abridged schematic for surface phase alternative pathway (AP) Figure 1 continued on next page 
Figure 1 continued

activation in assays (where generation of C3b from the CP/LP is virtually excluded); tick-over of C3 generates C3a (not shown) and C3b. In the presence of factor $\mathrm{B}$ and factor $\mathrm{D}, \mathrm{C} 3 \mathrm{bBb}$ (the $\mathrm{AP} C 3$ convertase) generates additional $\mathrm{C} 3 \mathrm{~b}$, prompting formation of $\mathrm{C} 3 \mathrm{bBbC} 3 \mathrm{~b}$ (the $\mathrm{AP}$ C5 convertase), which cleaves C5 into C5a and C5b, driving MAC formation. CP-driven ELISAs (C) and AP-driven ELISAs (D) are shown. For both pathways, the inhibition of C3d (the surface-associated domain of C3b, which is upstream of C5 inhibition), C5a release, and C5b neo-epitope formation and C9 deposition were tracked within the MAC. Haemolysis assays with sheep erythrocytes, for the CP (E), and rabbit erythrocytes, for the AP (F), show that K57 is a potent and efficacious inhibitor of both pathways. K92 is selective, partial antagonist of the AP, while K8 is a weak antagonist of the CP but did not show efficacy in the AP haemolysis assay, below $10 \mu \mathrm{M}$. For the AP assays, $5 \%$ serum (v/v) gives a putative $\mathrm{C} 5$ concentration of $20 \mathrm{nM}$. For the CP assays, $1 \%$ serum ( $/ \mathrm{v}$ ) gives a putative $C 5$ concentration of $4 \mathrm{nM}$, based on a reported C5 serum concentration of $397 \mathrm{nM} / 75 \mu \mathrm{g} / \mathrm{mL}$ (Sjöholm, 1975).

\section{Cooperativity in $\mathbf{C} 5$ binding by knob domain peptides}

To test for cross blocking, arising from overlapping epitopes, or cooperativity between knob domains, we performed a surface plasmon resonance (SPR) cross blocking experiment, where, using a Biacore 8K, we saturated a C5-coated sensor chip with two $20 \mu \mathrm{M}$ injections of knob domain peptide before injecting a different peptide at $20 \mu \mathrm{M}$ to assess its capacity to bind. This provides a qualitative measure of cross blocking, whereby an increase in response units (RUs) indicates ternary complex formation, stoichiometries, or kinetics cannot be reliably derived with concurrent dissociation of both peptides (Figure 2).

Saturation of $\mathrm{C} 5$ with $\mathrm{K} 8, \mathrm{~K} 57$, or $\mathrm{K} 92$ did not prevent subsequent binding of the non-functional K149 (Figure 2D), suggesting K149 does not share an epitope with the other ligands, nor does it significantly perturb $\mathrm{C} 5$ such that the other binding sites are affected.

We detected negative cooperativity between $\mathrm{K} 8$ and $\mathrm{K} 92$, whereby saturation of $\mathrm{C} 5$ with $\mathrm{K} 8$ entirely prevented binding of K92. When the order of addition was changed and C5 was saturated with K92, K8 was still able to bind, albeit to a lesser degree (Figure 2B). Saturation of C5 with K8 also entirely eliminated binding of $\mathrm{K} 57$, with a similar order of addition effect, whereby $\mathrm{K} 8$ could still partially bind to the C5-K57 complex (Figure 2A). When C5 was saturated with K92 or K57, only very small amounts of subsequent binding of either peptide were observed by SPR (Figure 2C), suggesting that the epitopes do not overlap but that considerable negative cooperativity exists.

\section{Structural analysis of C5-knob domain complexes}

\section{Crystal structure of the C5-K8 peptide complex}

To elucidate the structural basis for the allosteric modulation of $\mathrm{C} 5$, we determined the crystal structure of the C5-K8 complex at a resolution of $2.3 \AA$ (see Supplementary file 1, Table 2.1 for data collection and structure refinement statistics). The structure of the C5-K8 complex shows the K8 peptide binding to a previously unrecognised regulatory site on C5; the macroglobulin (MG) 8 domain of the $\alpha$-chain (Figure 3A). K8 adopts a cysteine knot-like configuration, where a flattened 3 -strand $\beta$-sheet topology is constrained by three disulphide bonds (Figure 3A and Figure 3-figure supplement 1A). Analysis of the K8-C5 complex with the macromolecular interfaces analysis tool PDBePISA (Krissinel and Henrick, 2007) reveals a large interaction surface (total buried surface area in complex: $1642 \AA^{2}$; with $852 \AA^{2}$ contributed by $\mathrm{K} 8$ and $790 \AA^{2}$ by C5), comparable to those seen in Fab-antigen complexes (Ramaraj et al., 2012), stabilised by an extensive network of 18 hydrogen bonds between K8 and the MG8 domain (Figure 3A and Supplementary file 1), dominated by arginine residues $\mathrm{R} 23_{\mathrm{K} 8}, \mathrm{R} 32_{\mathrm{K} 8}$, and $\mathrm{R} 45_{\mathrm{K} 8}$. The extensive $\mathrm{H}$-bond network is further bolstered by several ionic interactions, between $\mathrm{R} 32_{\mathrm{K} 8}$ and $\mathrm{D} 1471_{\mathrm{C} 5}$ (C5 numbering based on mature sequence), $\mathrm{D} 25_{\mathrm{K} 8}$ and $\mathrm{K} 1409_{\mathrm{C} 5}$, and $\mathrm{H} 36_{\mathrm{K} 8}$ and $\mathrm{D} 1382_{\mathrm{C} 5}$ (Figure $3 \mathrm{~A}$ and Supplementary file 1 Table 2.3). The opposing face of $K 8$ was fortuitously stabilised by a substantial, $1275 \AA^{2}$, crystal contact with the $\mathrm{C} 5 \mathrm{~d}$ domain of a symmetry-related C5 molecule (Figure 3-figure supplement 1B), ensuring low relative $B$-factor values (K8: $58 \AA^{2}$, C5-K8 complex: $65 \AA^{2}$ ) (see also Figure 3-figure supplement $1 \mathrm{C}$ ) and clear and continuous electron density, enunciating the unique disulphide bond arrangement of the knob domain peptide and the backbone and side chains interactions with $\mathrm{C5}$ (Figure 3-figure supplement 2A shows a mFo-DFc simulated annealing OMIT map of the C5-K8 complex). Despite the overall resolution of the dataset comparing favourably with other C5 structures in the PDB (Schatz-Jakobsen et al., 2016; Laursen et al., 2010; Jore et al., 2016; Fredslund et al., 2008), density for the C345c domain was largely absent due to this flexible domain occupying a solvent channel. This flexible attachment of the C345c domain to the $\alpha$-chain of C5 is 

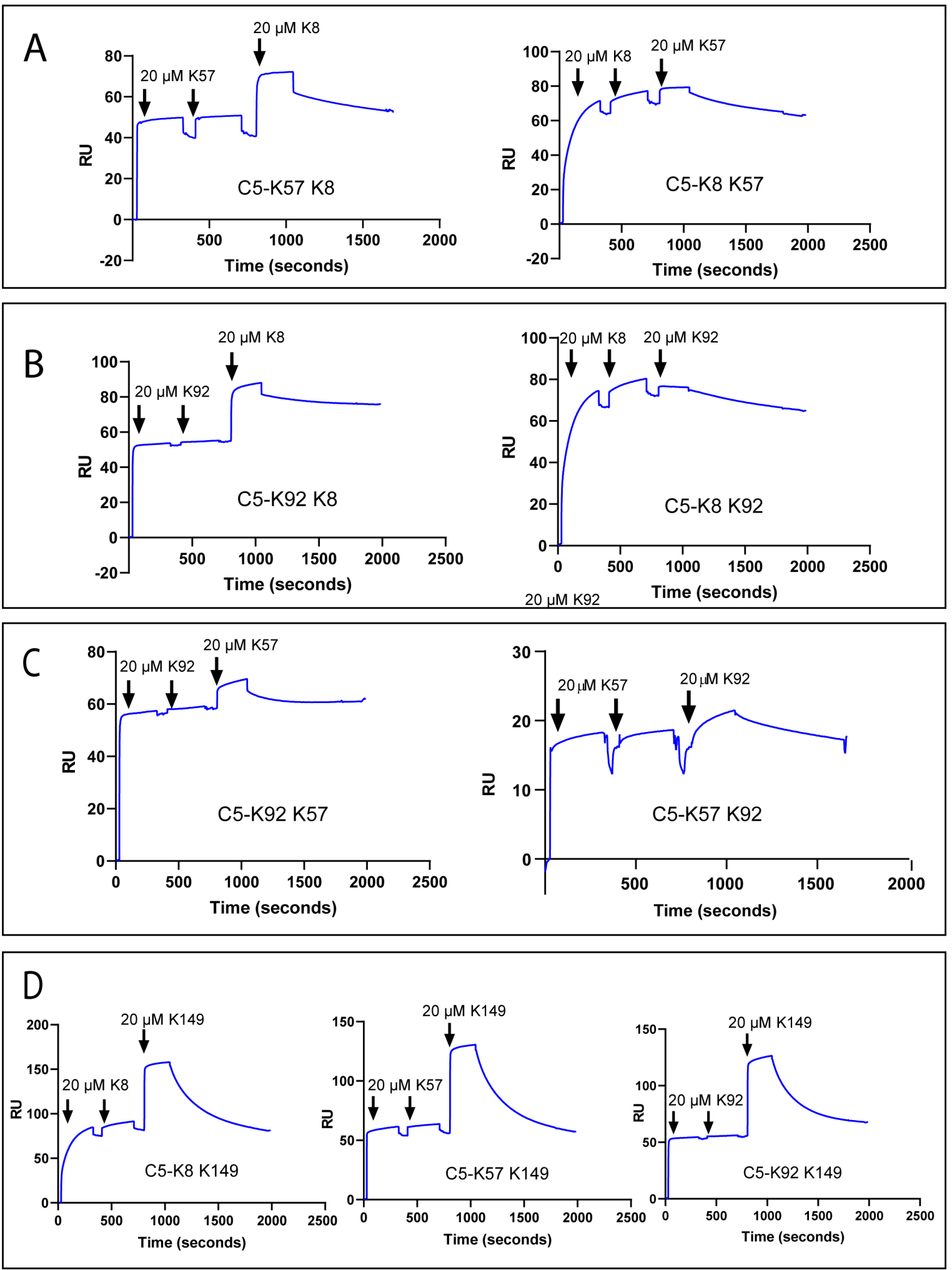

Figure 2. Surface plasmon resonance peptide cross blocking. (A), (B), and (C) highlight negative cooperativity between the K8, K92, and K57 peptides, respectively. Neither K57 or K92 can bind to the C5-K8 complex but K8 can bind, albeit at a lower level, to C5-K57 and C5-K92. We could not detect any negative cooperativity between K8, K57, or K92 with the silent binder K149, shown in (D). RU: response unit. 


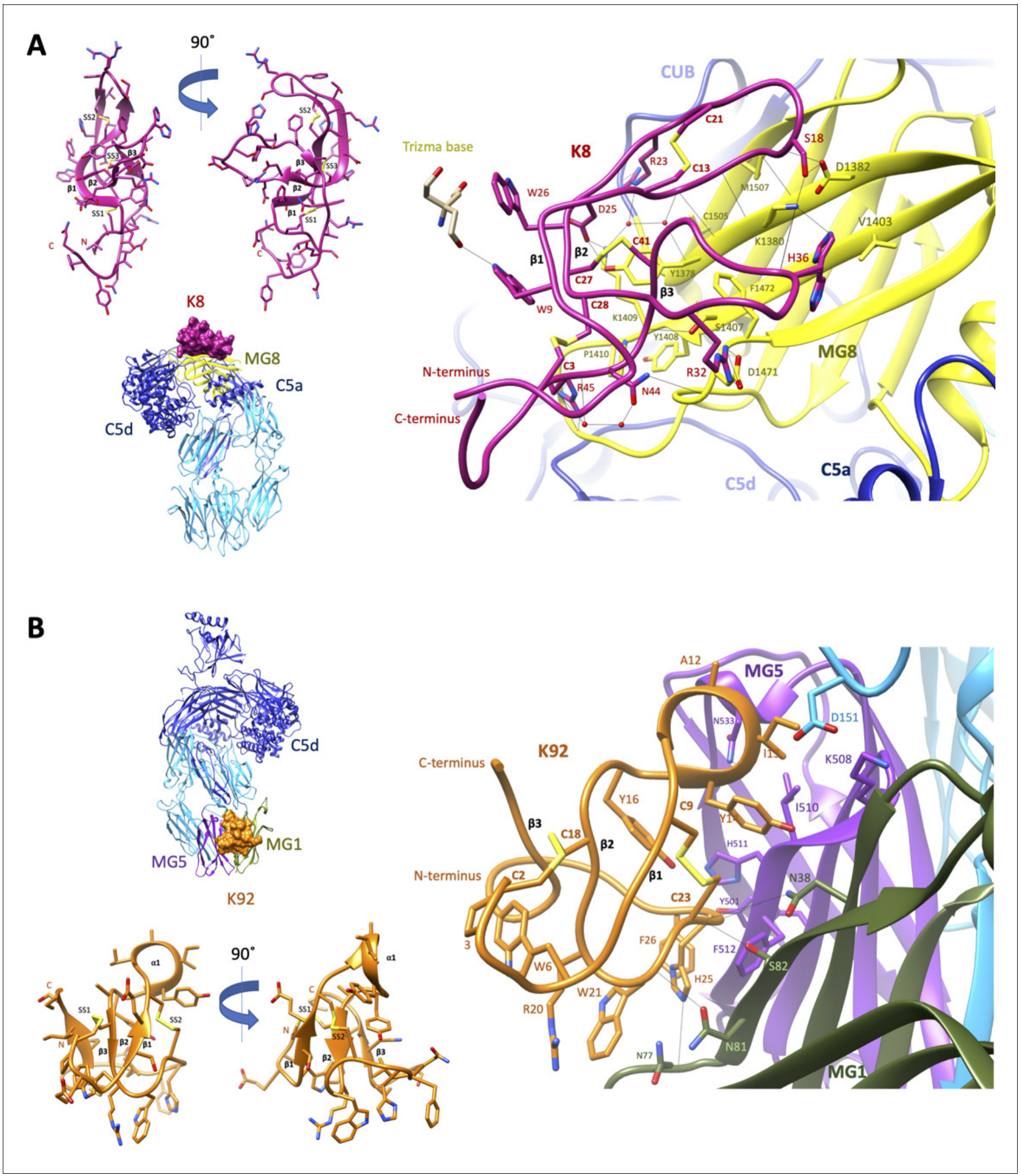

Figure 3. Crystal structures of C5-knob domain complexes. (A) and (B) show the crystal structures of C5 in complex with the K8 and K92 knob domain peptides, respectively. The binding site for the K8 peptide ( $A$, shown in red) is located on a previously unreported ligand binding site on the macroglobulin (MG) 8 domain (shown in yellow) of C5. The binding site for K92 ( $B$, shown in orange) is located between the MG1 and MG5 domains (shown in green and magenta, respectively).

Figure 3 continued on next page 
Figure 3 continued

The online version of this article includes the following figure supplement(s) for figure 3 :

Figure supplement 1. Structural analysis of the C5-K8 complex.

Figure supplement 2. Simulated annealing OMIT maps of the C5-knob domain peptide complexes.

Figure supplement 3. Structural analysis of the C5-K92 complex.

Figure supplement 4. Paratope analysis of $\mathrm{K} 8$ and $\mathrm{K} 92$ peptides.

observed consistently across the C5 structures (Schatz-Jakobsen et al., 2016; Laursen et al., 2010; Jore et al., 2016; Fredslund et al., 2008).

\section{Crystal structure of the C5-K92 complex}

We also present a crystal structure of the C5-K92 complex at a resolution of $2.75 \AA$ (see Supplementary file 1 for data collection and structure refinement statistics). Continuous electron density for the flexible C345c domain of C5 was observed due to it being stabilised in an upward pose by crystal contacts, akin to the $\mathrm{C} 5-\mathrm{RaCl}-\mathrm{OmCl}$ ternary complex structures (Protein Data Bank [PDB] accession codes 5HCC, 5HCD, and 5HCE; Jore et al., 2016). Despite displaying higher affinity binding to $\mathrm{C} 5$ than $\mathrm{K} 8$, electron density for $\mathrm{K} 92$ was less well defined as it occupies a solvent channel, and stabilising crystal packing interactions are absent (Figure 3-figure supplement 3B). A mFo-DFc simulated annealing OMIT map of the C5-K92 complex is displayed in Figure 3-figure supplement $2 \mathrm{~B}$, showing clear but sparse electron density for the peptide at $1.3 \sigma$. Correspondingly, only a small increase in $\mathrm{R}_{\mathrm{free}}$ of $25.35-25.53$, is observed when the peptide is removed during refinement compared to an increase in $\mathrm{R}_{\text {free }}$ of 23.36-27.08 upon removal of the K8 peptide, potentially indicating that the occupancy is significantly below 1 . This is also reflected in the high relative B-factor values for K92 (182.5 $\AA^{2}$ ) compared to that of the complex $\left(100.5 \AA^{2}\right.$ ) (see also Figure 3figure supplement $3 \mathrm{C}$ ). Model building of the $\mathrm{K} 92$ peptide was aided by disulphide mapping using mass spectrometry. The disulphide map of K92 identified formation of disulphide bonds between $\mathrm{C} 9_{\mathrm{K} 92}$ and $\mathrm{C} 23_{\mathrm{K} 92}$ and between $\mathrm{C} 2_{\mathrm{K} 92}$ and $\mathrm{C} 18_{\mathrm{K} 92}$ (Supplementary file 1, Table 2.4), enabling completion of the model.

Similar to K8, K92 adopts a 3-strand $\beta$-sheet topology (Figure 3B and Figure 3-figure supplement 3A) but stapled with only two disulphide bonds. With shorter $\beta$-strands and longer connecting loop regions, K92 exhibits a more compact, globular arrangement (Figure 3B). Two extended loop regions interact with $\mathrm{C} 5$, including an $\alpha$-helix containing loop between $\beta$-strands 1 and 2 , occupying a cleft between the MG1 and MG5 domains of the $\beta$-chain of C5. The interaction surface (total buried surface area: $1365 \AA^{2}$; with $750 \AA^{2}$ contributed by $\mathrm{K} 92$ and $615 \AA^{2}$ by C5) is sustained via a sparse set of eight $\mathrm{H}$-bonds (Supplementary file 1, Table 2.5). A series of $\pi-\pi$ and aliphatic-aromatic stacking interactions spans $\mathrm{K} 92$, encompassing $\mathrm{F} 26_{\mathrm{K} 92}, \mathrm{H} 25_{\mathrm{K} 92}, \mathrm{~W} 21_{\mathrm{K} 92}, \mathrm{~W} 6_{\mathrm{K} 92}$, and $\mathrm{P} 3_{\mathrm{K} 92}$ (Figure 3B). From within this hydrophobic patch, $\mathrm{H}$-bonds occur between $\mathrm{H} 25_{\mathrm{K} 92}$ and the backbone carbonyls of $\mathrm{N} 7_{\mathrm{C} 5}$ and $\mathrm{N} 81_{\mathrm{C} 5}$ on the MG1 domain.

\section{Validation of the observed C5-peptide complexes}

To validate the observed $\mathrm{K} 8$ and $\mathrm{K} 92 \mathrm{C} 5$-binding modes observed in our crystal structures, we assessed the binding properties for a number of alanine mutants of K8 and K92. For K8, R23A and R32A mutants targeted the two salt-bridge interactions with $\mathrm{C} 5$. While for K92, where there were few electrostatic interactions mediated by side chains, we targeted a hydrogen bond, sustained by $\mathrm{H} 25$, and important hydrophobic interactions with $\mathrm{C} 5$, involving neighbouring aromatics W21 and F26. While the K92 H25A mutant could not be expressed, the other mutants were tested, alongside unmodified $\mathrm{K} 8$ and $\mathrm{K} 92$, in SPR multi-cycle kinetics experiments $(n=3)$. For K8, the R23A resulted in modest twofold decrease in affinity, but R32A was markedly more attenuating, with a 715-fold drop in affinity (Supplementary file 1, Table 2.6). For K92, the loss of hydrophobic interactions with C5 in W21A and F26A mutants markedly abridged affinity with a 1209.2-fold and 45.7-fold drop in affinity, respectively (Supplementary file 1, Table 2.6).

To analyse the interfaces observed in the structures, we performed binding pose metadynamics (Clark et al., 2016), an analysis typically employed to computationally evaluate the binding stability of chemical ligands (Fusani et al., 2020). This in silico analysis suggested that both 
K8 and K92's binding poses were exceptionally stable, with the interface maintaining the key interactions in spite of applied force (Supplementary file 1, Tables 2.7 and 2.8). This, in conjunction with earlier kinetic studies (Macpherson et al., 2020), highlights the stability of the interactions made by both knob domains.

\section{Cysteines participate in inter- and intra-paratope interactions}

In the near absence of secondary structure, disulphide bonds appear to act as sources of stability for both peptides. For $\mathrm{K} 92$, both the backbone amide and carbonyl of $\mathrm{C}_{2} 3_{\mathrm{K} 92}$ participate in $\mathrm{H}$-bonds with the side chain of $\mathrm{S}_{8} 2_{\mathrm{C} 5}$ (Figure $3 \mathrm{~B}$ ). For $\mathrm{K} 8$, an interchain sulphur- $\pi$ stack between the $\mathrm{C}_{2} 7_{\mathrm{K} 8^{-}}$ $\mathrm{C} 41_{\mathrm{K} 8}$ disulphide bond and the aromatic of $\mathrm{Y} 1378_{\mathrm{C} 5}$ positions the hydroxyl group of $\mathrm{Y} 1378_{\mathrm{C} 5}$ to make a H-bond with D25 $5_{\mathrm{K} 8}$ (Figure $3 \mathrm{~A}$ ). While for $\mathrm{K} 92$, an intra-chain sulphur- $\pi$ stack between the $\mathrm{C}_{\mathrm{K} 92}-\mathrm{C} 23_{\mathrm{K} 92}$ disulphide bond and the aromatic of $\mathrm{Y}_{1} 4_{\mathrm{K} 92}$ orientates $\mathrm{Y} 14_{\mathrm{K} 92}$, such that its hydroxyl group participates in an interchain $\mathrm{H}$-bond with $\mathrm{N} 38_{\mathrm{C} 5}$.

\section{Comparison to known antibody paratopes}

Although antibody-derived, $\mathrm{K} 8$ and $\mathrm{K} 92$ are structurally unique variable regions. We compared the $\mathrm{K} 8$ and $\mathrm{K} 92 \mathrm{knob}$ domains to a non-redundant set of 924 non-identical sequences of paired antibody-protein antigen structures from SAbDab (Dunbar et al., 2014). Paratopes were defined as any antibody residues within $4.5 \AA$ of the antigen in the structure. The paratopes of K8 and K92 contain 18 and 10 residues, respectively, which are within the typical range of antibody paratope sizes (Figure 3-figure supplement 4A). Given this similarity in size, we searched for structurally and physicochemically similar antibody paratopes from the 924 antibody complexes but no similar paratope sites were found (Wong et al., 2020). While the limited examples preclude firm conclusions, this lack of similarity could be due to either the unusual fold of the knob domains or the differences in paratope amino acid composition.

In terms of residue usage, one difference in paratope composition that is potentially universal is the presence of cysteine in the knob domains (Figure 3-figure supplement 4B) which is uncommon in most antibody paratopes, with the exception of the CDR1-CDR3 disulphides, which have been described in camelid VHH (Govaert et al., 2012), and in broadly neutralising antibodies; those which cross react with several strains of a virus, and for which a disulphide bond in CDRH3 has been described in antibodies against HIV-1 (Hutchinson et al., 2019) and hepatitis C (Flyak et al., 2018). Using Arpeggio (Jubb, 2015) to identify inter- (antigen contacting) and intra-paratope interactions (hydrogen bond, polar, ionic, and hydrophobic) revealed that, on average, antibodies have 16 intraparatope and 17 inter-paratope interactions; K8 is very close to this, with 15 intra-paratope and 17 inter-paratope interactions, whereas K92 paratope has fewer, with 9 intra-paratope and 10 inter-paratope interactions. A bovine Fab with an ul-CDRH3 was recently crystallised in complex with antigen, in this case a soluble portion of the HIV envelope (Stanfield et al., 2020). While the low resolution of the crystal structure hindered analysis, a casual inspection of the paratope suggests that 10 intraparatope and 10 inter-paratope interactions are sustained by the knob domain, comparable to K92.

A search for structurally homologous proteins, using the DALI protein structure comparison server (Holm, 2020), did not find any 3D structures similar to K8 or K92, including the 14 known structures of bovine Fabs with ul-CDRH3 in the PDB. These results highlight the heterogeneity of these structural elements of the bovine immune system which likely arise through selection against a specific antigen/epitope. We next looked at homology with cyclic peptides. A recent review summarised the interactions mediated by cyclic peptides bound to proteins, across 65 co-crystal structures in the PDB (Malde et alo, 2019). This revealed that cyclic peptides on average sustain eight electrostatic interactions with their protein target, with a range of $1-20$. When we consider K8, its 19 inter-paratope interactions are comparatively high for a peptide, while the seven inter-paratope interactions of $\mathrm{K} 92$ are far more typical (Figure 3-figure supplement 4C).

\section{The structural basis for allosteric inhibition of $\mathrm{C} 5$ by $\mathrm{K} 8$ and $\mathrm{K} 92$}

When compared to the binding sites of other C5 modulators (Figure 4A), it can be observed that the epitope for $\mathrm{K} 92$ is entirely contained within the binding interface of a previously reported immune evasion molecule, the $23 \mathrm{kDa}$ SSL7 protein from S. aureus (Figure 4B). While the C5-SSL7 structure reveals a shallow binding site involving a series of five $\mathrm{H}$-bonds between SSL7 and a region 


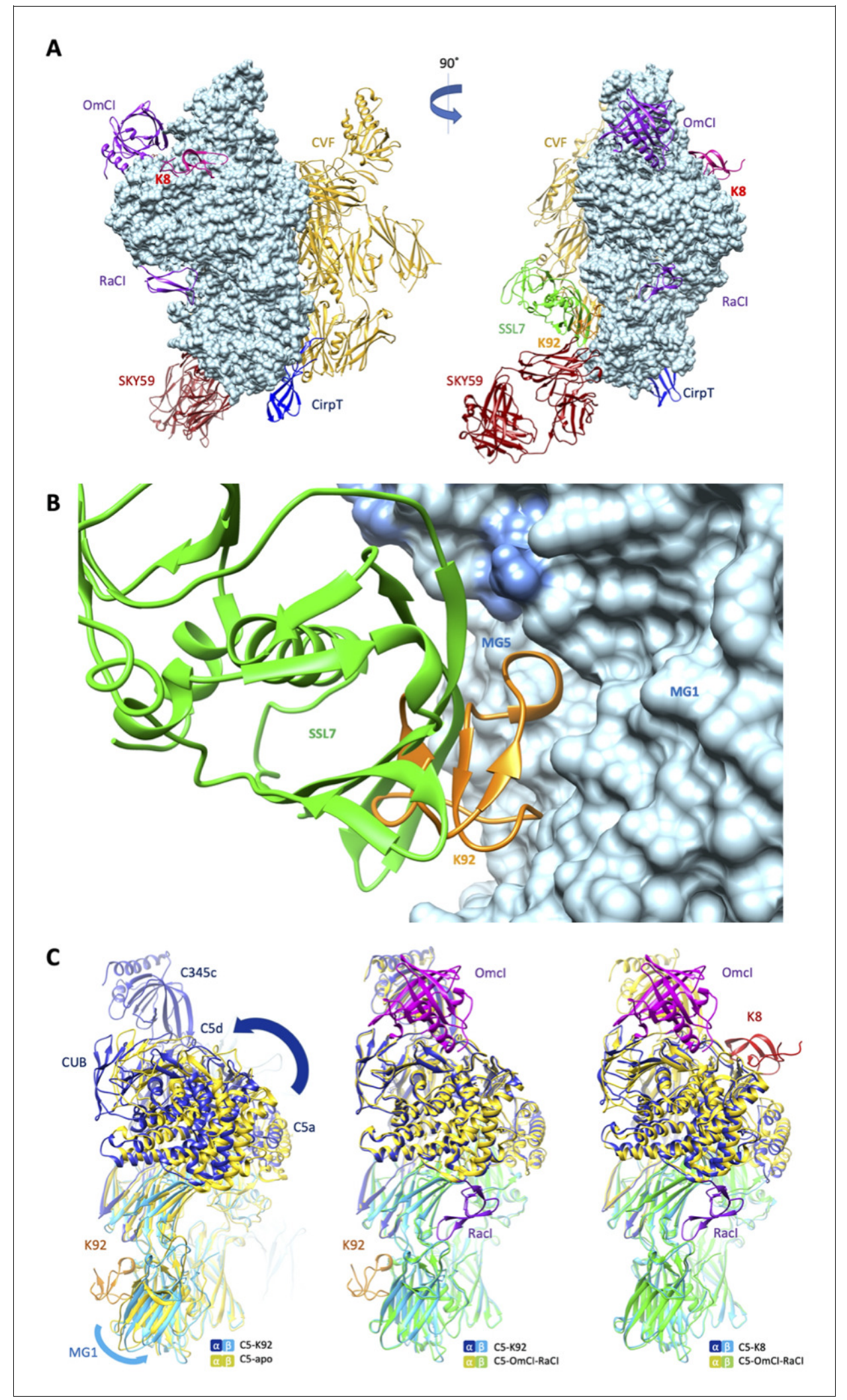

Figure 4. Comparison of the $\mathrm{K} 8$ and $\mathrm{K} 92$ binding sites with known $\mathrm{C} 5$ inhibitor complexes. Structural alignment of the complexes of $\mathrm{C} 5$ with the $\mathrm{K} 8$ and K92 knob domain peptides with the known structures for $\mathrm{OmCl}$ and $\mathrm{RaCl}$ (Protein Data Bank [PDB] accession code 5HCC; Jore et al., 2016), SSL7 and cobra venom factor (CVF) (PDB accession code 3PRX; Laursen et al., 2011), Cirp-T (PDB accession code 6RPT; Reichhardt et al., 2020), and SKY59 (PDB accession code 5B71; Fukuzawa et al., 2017) using UCSF Chimera (Pettersen et al., 2004). Alignments have been performed globally except for Figure 4 continued on next page 
Figure 4 continued

instances where the inhibitor has been crystallised bound to a single domain of C5. (A) shows two views of the superimposed C5-inhibitor complexes, differing by a $90^{\circ}$ rotation. $\mathrm{C} 5$ is shown in molecular surface rendering, with ribbon representations of $\mathrm{OmCl}$ and $\mathrm{RaCl}$ in purple, $\mathrm{SSL7}$ in green, $\mathrm{CVF}$ in gold, SKY59 in dark red, K8 in bright red, and K92 in orange. (B) shows a close-up view of the K92 binding site with that of SSL7 superimposed, for comparison. In contrast with the superficial binding mode of SSL7, K92 is wedged between the macroglobulin (MG) 1 and MG5 domains of C5. (C) (left) shows that the interaction between $\mathrm{K} 92$ and $\mathrm{C} 5$ induces a slight separation of the MG1 and MG5 domains, resulting in a significant rotational movement of the C5a, C5d, and CUB domains, when compared to the C5-apo structure (PDB accession code 3CU7; Fredslund et al., 2008). (C) also shows that the complex with $\mathrm{OmCl}$ and $\mathrm{RaCl}$ (PDB accession code $5 \mathrm{HCC}$; Jore et alo, 2016) stabilises a similar conformation in $\mathrm{C} 5$ (C, middle) to that of $\mathrm{K} 92$, as well as $\mathrm{K} 8$ (C, right). For this structural comparison, the C5 MG5 domains of the complexes were superimposed. The online version of this article includes the following figure supplement(s) for figure 4:

Figure supplement 1. Structural comparison of C5-K92 and C5-CVF complexes.

of $\beta$-sheet on the MG5 domain, spanning H511 ${ }_{\mathrm{C} 5}-\mathrm{E} 516_{\mathrm{C} 5}$ (Laursen et al., 2010), here we show that K92 is wedged between the MG1 and MG5 domains, inducing a re-orientation of the side chain of $\mathrm{H} 511_{\mathrm{C} 5}$ and forming a backbone $\mathrm{H}$-bond with $\mathrm{F} 510_{\mathrm{C} 5}$. When comparing $\mathrm{K} 92$ and SSL7, the small changes observed in the binding pose achieve different allosteric effects; SSL7, either in isolation or in complex with its second ligand IgA, is full, or occasional partial, antagonist of both the AP and CP (Bestebroer et al., 2010; Laursen et al., 2010), while K92 is a selective partial antagonist of the AP.

Inspection of the $\mathrm{C} 5 \mathrm{a}$ anaphylatoxin domain reveals that the $\mathrm{C}$-terminus of the $\mathrm{C} 5 \mathrm{a}$ domain in the C5-K92 complex adopts a helical conformation, which is analogous to the C5-OmCl- $\mathrm{RaCl}$ complex, burying the Bb-cleavage site (R751). In other C5 structures (including C5-apo and C5-CVF), this linker adopts an extended conformation following an unstructured loop and only sparse continuous electron density was observed for the linker extending from MG6 to C5a in the C5-K8 complex, possibly suggesting its R751 scissile bond is more exposed.

When the MG5 domains in the C5-K92 complex and the C5-apo structure are superimposed (Figure 4C), a slight twist can be observed in the MG1 domain, caused by the binding of K92 and resulting in a significant rotational movement of the $\mathrm{C} 5 \alpha$-chain. A similar conformational change results from the binding of $\mathrm{OmCl}$ and $\mathrm{RaCl}$, and to some extent $\mathrm{K} 8$, as these structures are virtually superimposable. CVF can form a highly stable C3/C5 convertase, following incubation with factor D and factor B in the presence of $\mathrm{Mg}^{2+}$ (Vogel and Müller-Eberhard, 1982), which may offer a surrogate model for C5 convertase (Laursen et al., 2011). When superimposing C5-K92 and C5-CVF (PDB accession code 3PVM) complexes, C5 does not adopt a similar conformation as when bound by $\mathrm{K} 92$ and $\mathrm{K} 8$ (Figure 4-figure supplement 1), potentially indicating both knob domains stabilise a different $\mathrm{C} 5$ conformation than binds the $\mathrm{C} 5$ convertase.

When considering the organisation of the C5 convertases, the C5-CVF crystal structure reveals that CVF and C5 align perfectly to create a mirror image complex, with a conformational change in the C5 convertase site at arginine 751, potentially placing C5a within range of the catalytic unit of the MG7-associated convertase complex, offering a surrogate model for C5 convertase activation (Laursen et al., 2011). We have shown that $K 92$ is not an orthosteric inhibitor of either the $\mathrm{CP}$ or the AP convertase, thereby precluding binding of the convertase to a cleft between the MG1MG5 domains. As the K92 epitope is entirely contained within the SSL7 binding site, this is compatible with the CVF model for C5 activation, with a co-crystal structure of the ternary complex of C5, CVF, and SSL7 (PDB accession code 3PRX6), demonstrating that the CVF and SSL7 binding sites do not cross block. Also consistent with the CVF model for C5 activation, binding of K8 to the MG8 domain would not appear to sterically block the catalytic unit. We therefore sought to further explore the apparent conformational changes in our structures.

\section{Solution techniques reveal allosteric networks}

To validate the apparent conformational changes occurring in $\mathrm{C} 5$ due to the binding of $\mathrm{K} 8$ and $\mathrm{K} 92$ as revealed by our crystal structures, we analysed the C5-knob domain complexes by two-solution biophysical techniques - small-angle X-ray scattering (SAXS) and hydrogen-deuterium exchange mass spectrometry (HDX-MS).

SEC-SAXS, where size exclusion chromatography (SEC) immediately precedes the solution X-ray experiment ensuring a monodispersed sample, was performed in concert with SEC multi-angle laser 
light scattering (SEC-MALLS). Data were collected for C5 and the C5-K8, C5-K57, C5-K92, and C5K149 complexes (Figure 5A-C). SEC-MALLS confirmed that the increases in molecular weight of the complexes were consistent throughout the elution peaks (Supplementary file 1, Table 3.1 and Figure 5-figure supplement 1A). While SEC-SAXS elution profiles gave stable estimates of the radius of gyration $\left(R_{\mathrm{G}}\right)$ across the tip of the peak, frames (scattering curves collected during the elution of the sample) from the descending elution peaks show lower $R_{G}$ values, suggesting the presence of unbound $\mathrm{C} 5$.

A

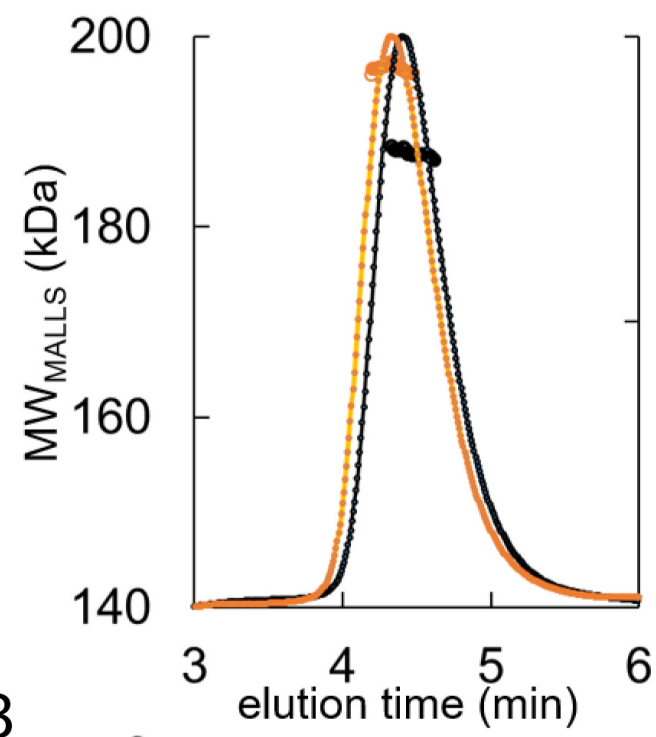

1.0

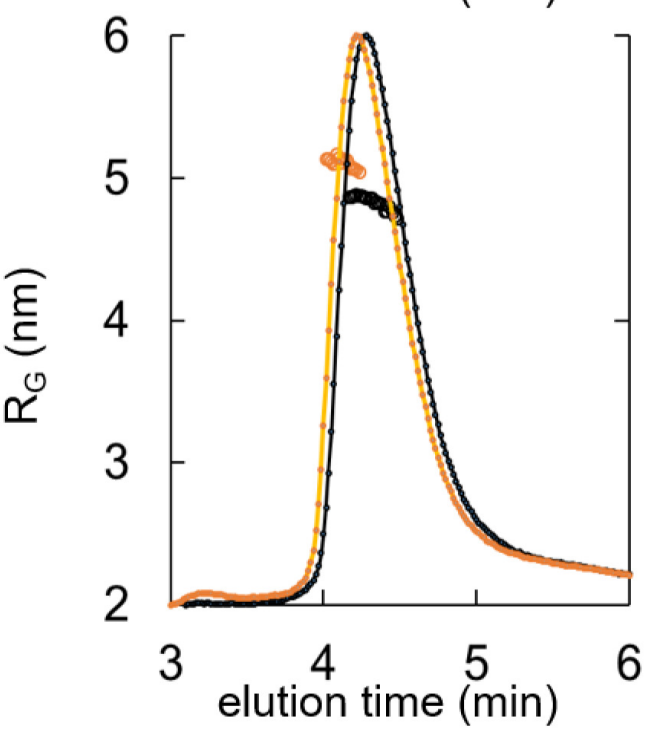

1.0

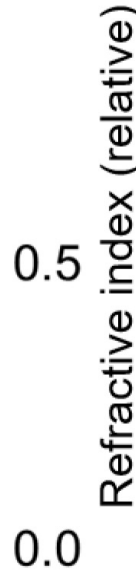

C

0.0

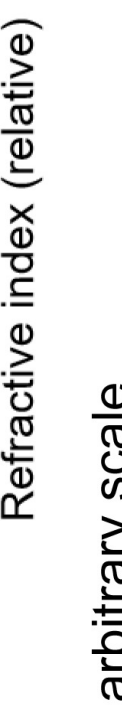

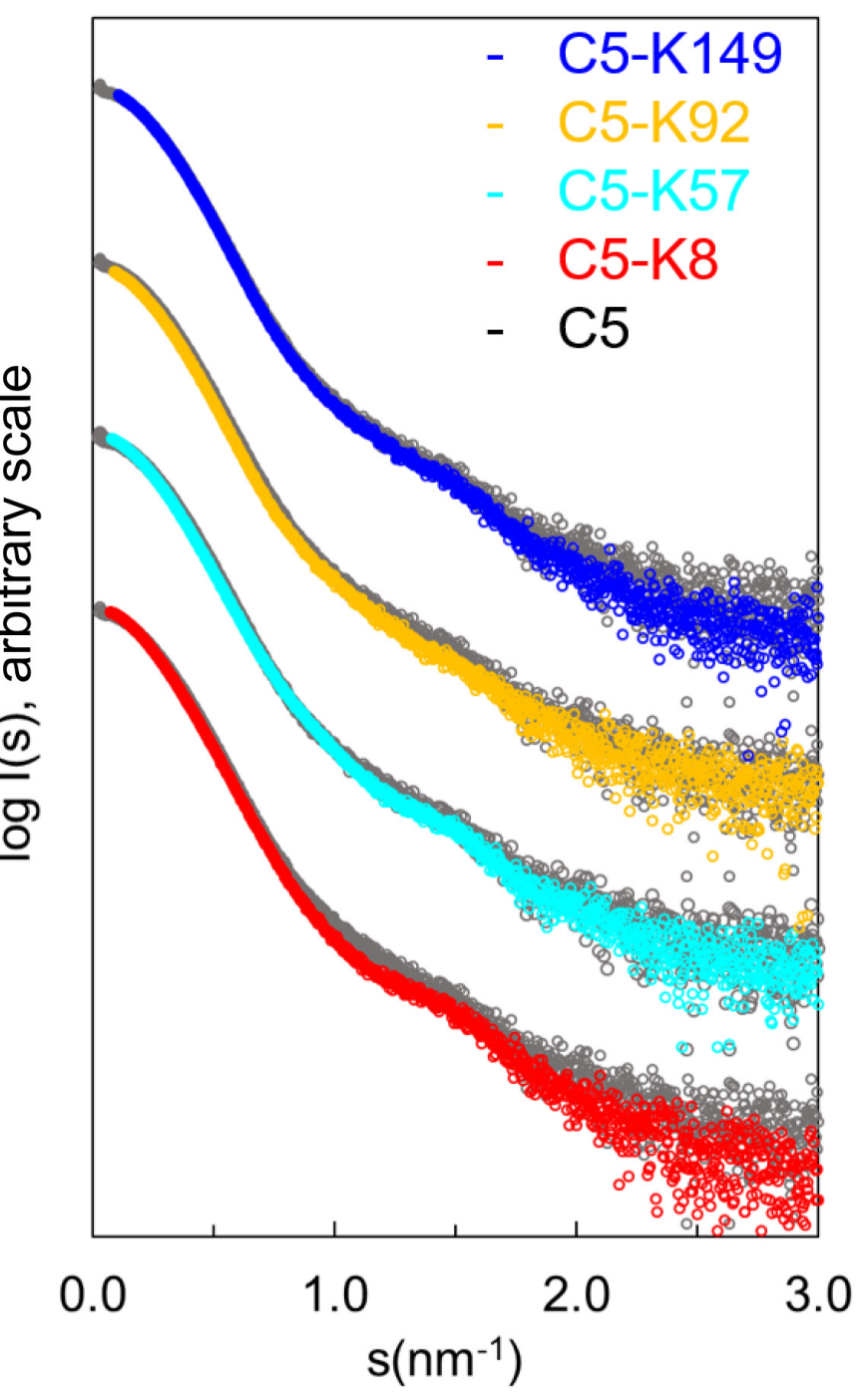

Figure 5. Hydrodynamic properties and solution conformation of C5 and C5-knob domain complexes by small-angle X-ray scattering (SAXS). Size exclusion chromatography multi-angle laser light scattering (SEC-MALLS) chromatograms (A) for apo C5 (black) and C5-K92 (orange) show a homogenous molecular weight increase across the C5-K92 elution peak. The SEC-SAXS elution profile collected under identical experimental conditions (B) shows an increase in radius of gyration $\left(R_{G}\right)$ for the C5-K92 complex. Scattering curves of all C5-knob domains are shown (C); the C5-knob domain complexes are shown against apo C5 (in grey), and for ease of viewing, the curves are arbitrarily shifted in the $Y$ axis.

The online version of this article includes the following figure supplement(s) for figure 5 :

Figure supplement 1. SAXS analyses of the C5-knob domain peptide complexes. 
Frames corresponding to the tip of the peak were averaged and submitted for full SAXS analysis. For the complexes, the scattering curves showed slight increases in both the $\mathrm{R}_{\mathrm{G}}$ and solute volume (Supplementary file 1, Table 3.1), with the C5-K8 complex showing the largest change and C5-K149 the smallest change, corresponding with the absence of function and suggesting K149 binds peripherally to a conformation closely resembling $\mathrm{C} 5$-apo. For $\mathrm{K} 92$ and $\mathrm{K} 57$, the discrepancies observed in the mid s range indicate an overall change in flexibility of $\mathrm{C} 5$ upon binding of these peptides, and this tuning of dynamics may contribute to their mechanism.

Consistent with earlier observations (Fredslund et al., 2008), comparison of the C5-apo experimental data with the theoretical scattering curve revealed discrepancies in the lowest angle range, indicating $\mathrm{C} 5$ adopts a more elongated conformation in solution than the crystal structure would suggest (Figure 5-figure supplement 1B). To better approximate C5 in solution, we performed a normal mode model analysis (NMA) using SREFLEX (Panjkovich and Svergun, 2016) and found that elongation of the C5 model improved the $\chi^{2}$ from $>13$ to 1.55 . The fit of the C5-K92 complex was also markedly improved by the NMA, whereby elongation and incorporation of the peptide improved the model from an initial $\chi^{2}$ of $>20$, to 2.5 (with an overall root mean square [RMS] of 3.8 in both cases).

When using the C5-K8 co-crystal structure for fitting of the C5-K8 SAXS data, the absence of the $\mathrm{C} 345 \mathrm{c}$ domain was problematic. The generation of a hybrid model where the $\mathrm{C} 345 \mathrm{c}$ domain was reinstated initially produced a poor fit $\left(\chi^{2}=75\right)$. A restrained rigid body analysis of this model followed by NMA refinement allowed us to significantly reduce the discrepancy to $\chi^{2}=4.1$ indicating an overall acceptable fit. The $\chi^{2}$ value is still somewhat larger than those observed for the other complexes, which may suggest an increased flexibility around the $\mathrm{C} 345 \mathrm{c}$ linker. This result correlates with the absence of clear electron density for the C345c domain in the crystal structure. The latter may be a consequence of $\mathrm{K} 8$ inducing additional flexibility to this region, which again could contribute to the efficacy of the peptide.

The discrepancies between the crystal structures and the solution scattering data indicate that while permitting elucidation of the molecular interaction of the epitopes, the constraints of the crystal lattice may impede the detection of more subtle, global changes, leading to underestimation of the conformational changes induced by the peptide.

To further explore such effects in solution, we used HDX-MS to provide molecular-level information on local protein structure and dynamics. HDX-MS measures the exchange of backbone amide hydrogen to deuterium in the solvent, with the rate of HDX determined by solvent accessibility, protein flexibility, and hydrogen bonding. To interpret the impact of peptide binding on C5 structural dynamics, we performed differential HDX $(\triangle \mathrm{HDX})$ analysis, comparing C5-knob domain complexes to apo $\mathrm{C} 5$, where shielding of $\mathrm{C} 5$ residues through participation in a binding interface will prevent deuteration, while conformational changes may increase or decrease deuterium uptake, in relation to the degree of solvent exposure.

For $\mathrm{C} 5-\mathrm{K} 8$, the sole protected region of $\mathrm{C} 5$ corresponded to the epitope on the MG8 domain $\left(\mathrm{L} 1380_{\mathrm{C} 5}-\mathrm{E} 1387_{\mathrm{C} 5}\right)$, although the interface was not entirely defined (Figure 6A, see also Figure 6figure supplement 1 and Supplementary file 1, Table 3.2). Additional conformational changes were observed in the neighbouring $\mathrm{C} 5 \mathrm{~d}$ domain which becomes more solvent exposed, suggesting $\mathrm{K} 8$ is affecting the dynamics of this domain.

For the $\mathrm{C} 5-\mathrm{K} 92$ complex, consistent with the crystal structure, there was protection of the $\mathrm{C} 5$ residues located in the epitope between the MG1 and MG5 domains $\left(\mathrm{H} 70_{\mathrm{C} 5}-\mathrm{L} 85_{\mathrm{C} 5}\right)$, shown in Figure 6 C. There were also effects distal to the K92 binding site, notably in $\mathrm{C} 5 \mathrm{~d}\left(11169_{\mathrm{C} 5}-\mathrm{F} 1227_{\mathrm{C}}\right)$ and neighbouring CUB domain ( $\left(1303_{\mathrm{C} 5}-\mathrm{L} 1346_{\mathrm{C} 5}\right.$ ), indicating a K92-induced conformational change. Interestingly, the allosteric network can be visualised by changes in solvent exposure which propagate from the K92 epitope through MG2 domain (L126 $\left.6_{C 5}-\mathrm{V} 145_{C 5}\right)$ and into the C5d and CUB domains. For the C5-K57 complex, the absence of a co-crystal structure meant we had no prior knowledge of the $\mathrm{K} 57$ epitope. However, clear protection was observed in the MG5 domain, immediately adjacent to the $\mathrm{K} 92$ epitope $\left(\mathrm{N} 483_{\mathrm{C} 5}-\mathrm{L} 540_{\mathrm{C} 5}\right)$, with sparse areas of increased solvent expo-

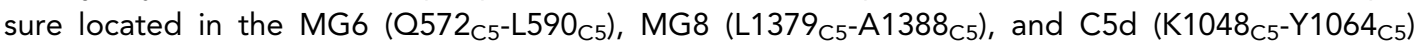
domains (Figure $6 \mathrm{~B}$ ). A single protected peptide was also present in the CUB domain ( $\mathrm{G} 951_{\mathrm{C5}^{-}}$ L967 ${ }_{C 5}$ ), suggesting the K57 epitope may be on either the MG5 or CUB domains.

There was little protection or deprotection of proteolytic fragments of the C5a domain in any of the complexes; we therefore propose that the knob domain peptides do not act by inducing 


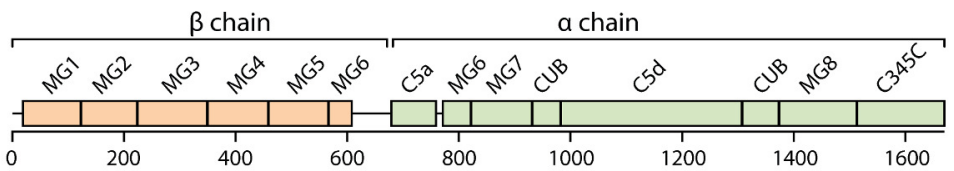

A $\quad \Delta \mathrm{HDX}=(\mathrm{C} 5+\mathrm{K} 8)-(\mathrm{C} 5)$

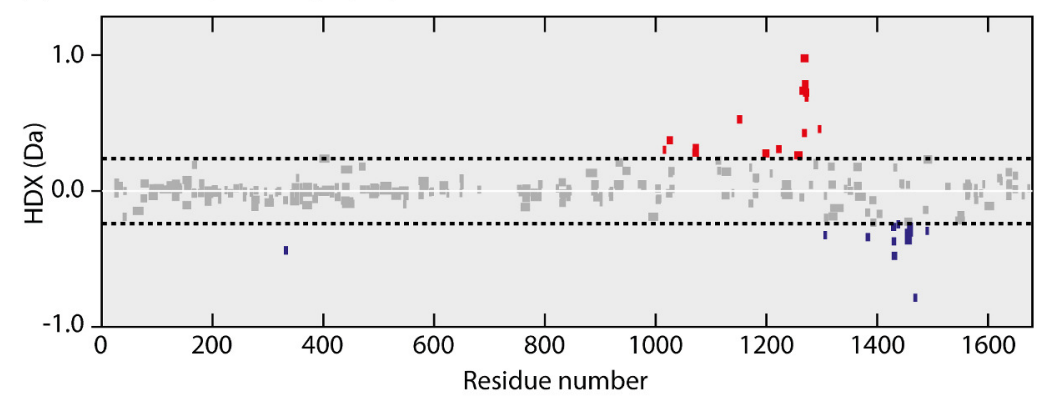

B $\quad \Delta \mathrm{HDX}=(\mathrm{C} 5+\mathrm{K} 57)-(\mathrm{C} 5)$

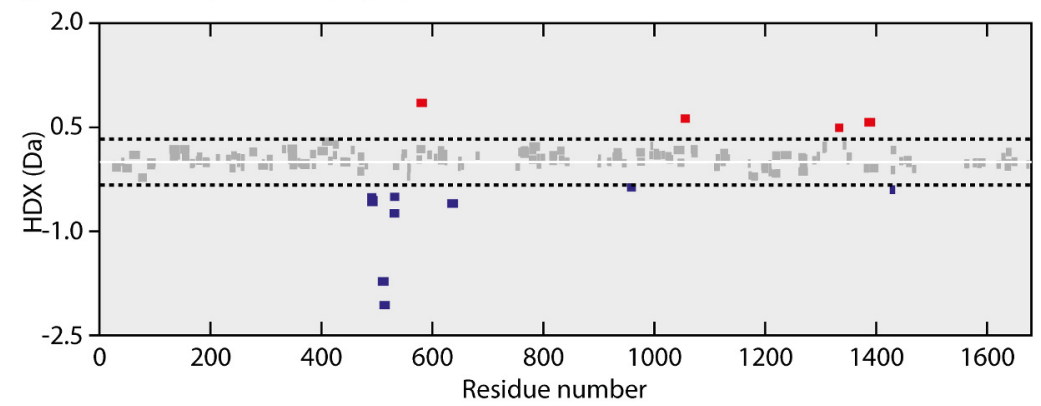

C $\quad \Delta \mathrm{HDX}=(\mathrm{C} 5+\mathrm{K} 92)-(\mathrm{C} 5)$

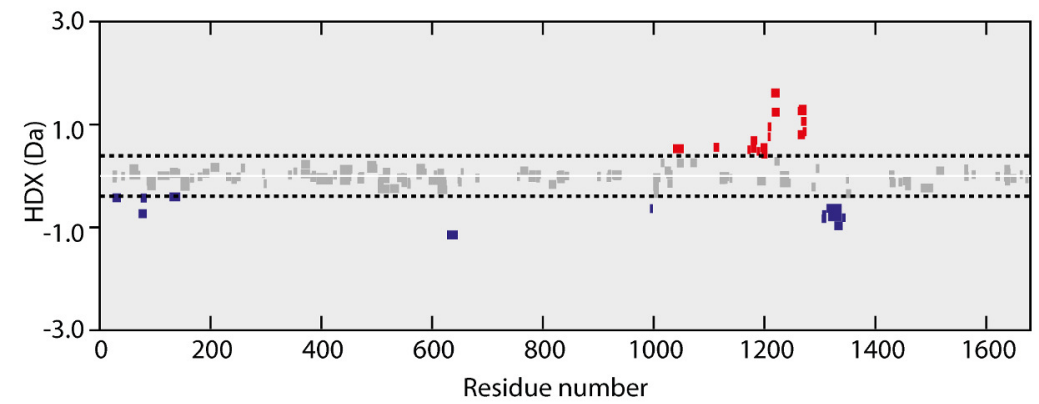

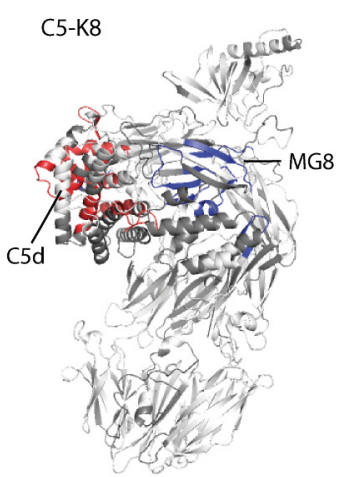

C5-K8
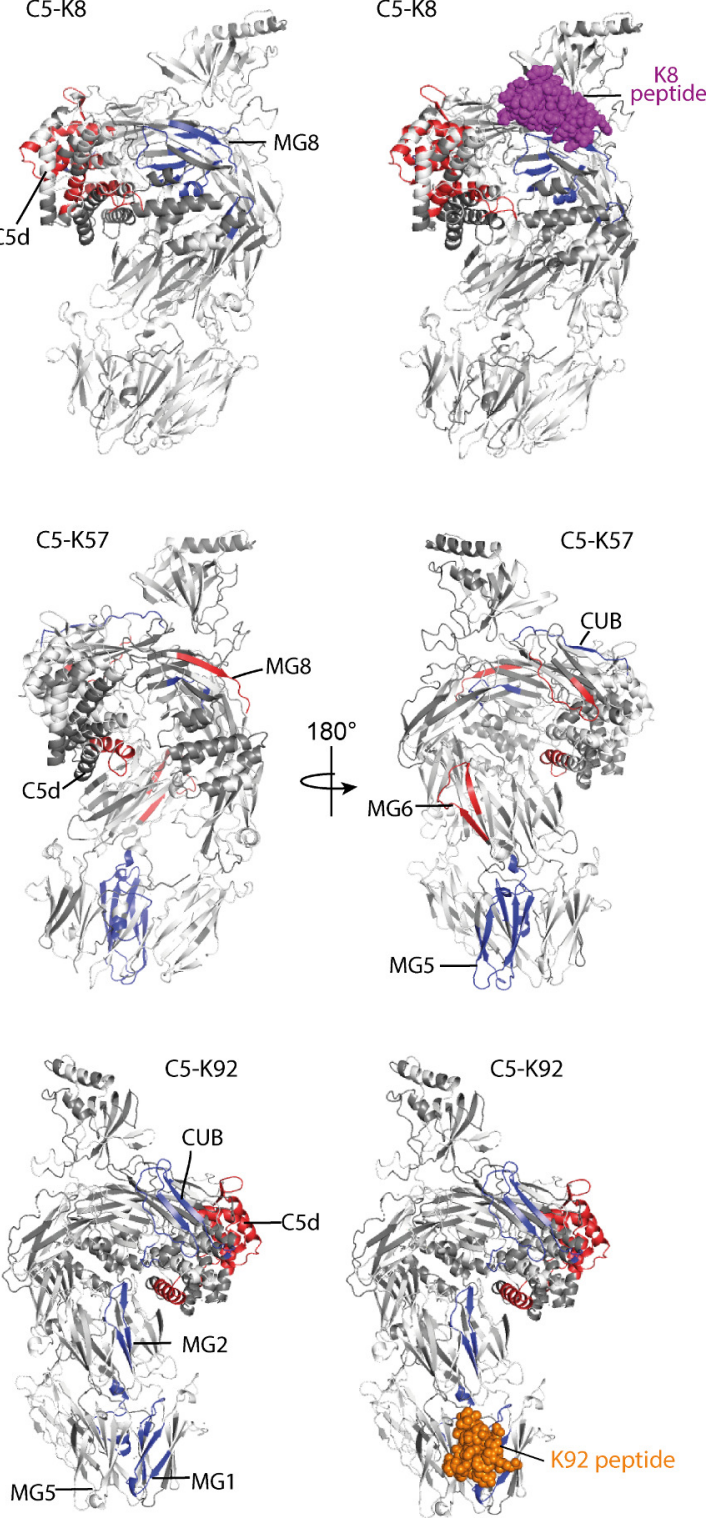

Figure 6. Impact of knob domain binding on the structural dynamics and conformation of $\mathrm{C} 5$. Differential hydrogen-deuterium exchange ( $\Delta \mathrm{HDX}$ ) plots for C5 in complex with knob domains (A) K8, (B) K57, and (C) K92 at 1 hr of deuterium exposure. Blue denotes peptides with decreased HDX (backbone $\mathrm{H}$-bond stabilisation), and red denotes peptides with increased HDX (backbone $\mathrm{H}$-bond destabilisation). $98 \%$ confidence intervals are shown as dotted lines. Peptides in grey have insignificant $\triangle \mathrm{HDX}$. Measurements were performed in triplicate, and all HDX-MS peptide data are detailed in

Supplementary file 1 Table 3.2. $\Delta \mathrm{HDX}$ for C5 + K8, C5 + K57, and C5 + K92 are coloured onto C5 (Protein Data Bank accession code 5HCC, minus $\mathrm{OmCl}$ and $\mathrm{RaCl}$ ).

The online version of this article includes the following figure supplement(s) for figure 6:

Figure supplement 1. HDX analyses of the C5-knob domain peptide complexes.

conformational changes which shield the scissile arginine bond. Although in the structure of the C5$\mathrm{K} 92$ complex the Bb-cleavage site is more buried compared to that in the C5-K8 complex. Taken in the context of the other changes, notably in the C5d and CUB domains, it is more probable that they affect more global changes in $\mathrm{C} 5$ which lower the affinity for $\mathrm{C} 3 \mathrm{~b}$ or the $\mathrm{C} 5$ convertases. The 
HDX-MS data are in good agreement with our crystallographic data, with the K8 and K92 epitopes defined as clear areas of solvent protection. The conformational change in the C5d domain and significant rotational moment of the $\mathrm{C} 5 \alpha$-chain, which were evident upon alignment of the MG1 domain of apo C5 with the C5-K8 and C5-K92 co-crystal structures, also appears to manifest in solution in response to binding of the knob domains.

\section{Putative K57 binding site}

To further home in on the $\mathrm{K} 57$ binding site, we measured binding to $\mathrm{C} 5 \mathrm{~b}$ and $\mathrm{C} 5 \mathrm{~b}-6$ in an SPR single-cycle kinetics experiment (Supplementary file 1, Table 4.1). Upon cleavage of C5a, the remaining domains of the $\alpha$-chain undergo a substantial conformational change, mediated by rearrangement of the MG8, CUB, and C5d domains (Hadders et al., 2012; Aleshin et al., 2012). The resulting $\mathrm{C} 5 \mathrm{~b}$ subunit is metastable and prone to aggregation and decay, which leaves it unable to bind C6 or form the MAC. By SPR, K8 did not bind C5b but could C5b-6. However, K57, K92, and $\mathrm{K} 149$ all bound C5b and C5b-6 (Supplementary file 1 Table 4.2). For C5b, this was within twofold of their previously published affinities for $\mathrm{C} 5(17.8 \mathrm{nM}$ for $\mathrm{K} 8,1.4 \mathrm{nM}$ for $\mathrm{K} 57$, and $<0.6 \mathrm{nM}$ for K92; Macpherson et al., 2020), except for K149, which displayed threefold higher affinity for both C5b and C5b-6 than previously reported for C5 (15.5 nM; Macpherson et al., 2020). K92 did exhibit lower affinity for C5b-6 complex than $\mathrm{C} 5$, binding the complex at $6.7 \mathrm{nM}$, relative to $<0.6 \mathrm{nM}$ for $\mathrm{C} 5$ alone. As the CUB domain is significantly altered in C5b, this increases the likelihood that, of the two protected regions identified by HDX-MS, the K57 epitope is on the MG5 domain.

\section{Discussion}

We present a new family of peptides, bovine antibody-derived knob domains, and show that, upon binding of the therapeutic target complement component C5 with high affinity, they display a range of inhibitory mechanisms. Knob domain peptides rely on the bovine immune system to achieve highaffinity binding through optimisation of amino acid composition, 3D structure, and disulphide bond network. They have only been recently isolated as a practicable antibody fragment (Macpherson et al., 2020), and therefore, structural and functional analysis of the complexes with their clinical targets will greatly aid their development as therapeutics.

\section{Function}

Functional characterisation at the level of individual complement pathways identified K57 as a novel C5 inhibitor, which is a fully efficacious inhibitor of the terminal pathway in response to both CP and AP activation, and a potential therapeutic candidate for complement-mediated disorders, such as paroxysmal nocturnal haemoglobinuria and atypical haemolytic uraemic syndrome. Additionally, the discovery of K149 as a 'silent binder' of C5 may be of considerable value as a non-inhibitory reagent for the detection of native C5 (Figure 1). K8 and K92 both displayed allosteric inhibitory activity against C5. K92 achieved selective inhibition of the AP through a non-competitive mechanism (Figure 1). To our knowledge, this is the first reported example of complement pathway-specific inhibition through $\mathrm{C} 5$ and the first experimental evidence reported for mechanistic differences between the AP and CP C5 convertases. This suggests an expanded therapeutic scope for C5, whereby tuning of the conformational ensemble or dynamics with allosteric compounds can bias activation to leave certain complement pathways intact. Complete inhibition of the terminal pathway has been shown to increase the susceptibility of eculizumab patients to Neisseria meningitidis infections (McNamara et al., 2017). Selective inhibition of C5-cleavage by the AP C5-convertase, and not the CP C5-convertase, may partially preserve serum bactericidal activity, thereby lowering the risk of meningococcal disease.

\section{Structure}

Structural analyses, utilising X-ray crystallography, revealed the unique topologies of knob domain peptides $\mathrm{K} 8$ and $\mathrm{K} 92$ and their distinctive binding modes in $\mathrm{C} 5$. Due to the apparent structural homology of knob domains with certain venomous peptides, of which conotoxins and spider venoms are examples, it has been proposed that the knob domains of ul-CDRH3 might be similarly predisposed to target the concave epitopes of ion channels. Likewise, structural homology with defensin peptides has garnered hypotheses regarding an improved ability to bind viral capsid coats. Indeed, 
bovine antibodies with $\mathrm{ul}-\mathrm{CDRH} 3$ have been raised against the viral capsid of HIV with exceptional efficiency, given the challenging nature of the antigen (Sok et al., 2017; Stanfield et al., 2020). However, the study presented here shows that, in the case of $\mathrm{C} 5$, concave epitopes are not the knob domain's sole preserve. Notably, the MG8 domain epitope of K8 offers a planar pharmacophore and, while the $\mathrm{K} 92$ epitope is more undulating, casual inspection of the $\mathrm{C} 5$ structure reveals numerous deeper cavities available (Figure 3). This may mean that knob domains can be raised to inhibit flat surfaces involved in protein-protein interactions, which might not offer binding sites for orthosteric small molecules.

We note that the structural architecture of the knob domains varies for the epitope. Their immune derivation means that, unlike cysteine-rich peptides derived from other natural sources, such as venoms, the bovine immune system can be used to define specificity for any antigen. Comparative structural analysis suggests that knob domain paratopes are differentiated from conventional antibodies and the structures of known cyclic peptides, offering a different binding architecture to other small antibody fragments, such as the camelid VHH. While firm conclusions are hampered by limited examples, the number of interactions does not seem dissimilar from cyclic peptides or mAbs, both of which have been successfully applied to tackling high-affinity protein-protein interactions.

Our structures demonstrate that the importance of the network of disulphide bonds goes beyond a stabilising role. An apparent paucity of secondary structure would suggest that while stabilisation of the domain is indeed critical, disulphide bonds also participate in sulphur- $\pi$ interactions to sustain intra- and inter-chain interactions. The structures of knob domains bound to their target antigen demonstrate both the diversity and versatility afforded to the bovine immune repertoire by these sequences.

\section{Mechanism}

Structural alignment of the C5-K92 co-crystal structure with the apo C5 structure (Figure 4), using the MG5 domain, revealed a rotational movement of the MG1 causing the $\alpha$-chain to adopt a twisted conformation accompanied by a rotational movement in the $\mathrm{C} 5 \mathrm{~d}$ domain, in response to knob domain binding. Comparison of the C5-K8 structure with the apo $\mathrm{C} 5$ structure revealed a similar conformation but with less movement in the C5d domain. The helical C5d domain is the target of two immune evasion molecules which have evolved in ticks, $\mathrm{OmCl}$ and $\mathrm{RaCl}$, both of which inhibit $\mathrm{C} 5$ by crosslinking $\mathrm{C} 5 \mathrm{~d}$ to neighbouring domains (Jore et al., 2016). Additionally, it has been shown that polyclonal antibodies raised against C5d inhibit binding of C5 to C3b (DiScipio, 1981). The binding site of $\mathrm{OmCl}$ is contained within the CUB and C5d domains, with only a single, non-bonded interaction to the $\mathrm{C} 345 \mathrm{c}$ domain visible in the crystal structure (Jore et al., 2016), which appears mediated by crystal contacts. Interestingly, the $\mathrm{C} 5-\mathrm{OmCl}-\mathrm{RaCl}$ crystal structure (PDB accession code $5 \mathrm{HCC}$ ) reveals similar conformational changes in $\mathrm{C} 5 \mathrm{~d}$, relative to the apo $\mathrm{C} 5$ structure. We therefore propose that rearrangement of $\mathrm{C} 5 \mathrm{~d}$ can lower the affinity, or preclude the interaction, of $\mathrm{C} 5$ for the convertases and that this may be a common inhibitory mechanism for $\mathrm{OmCl}, \mathrm{RaCl}, \mathrm{K} 8$, and $\mathrm{K} 92$. Should $\mathrm{K} 92$ and $\mathrm{K} 8$ inhibit $\mathrm{C} 5$ by modulating the $\mathrm{C} 5 \mathrm{~d}$ domain, in the case of $\mathrm{K} 92$, this occurs at a range of over $50 \AA$. Such remote effects are not unprecedented; allosteric structural changes can be propagated at over $150 \AA$ in response to drug binding (Haselbach et al., 2017).

Subsequent solution biophysics methods substantiate our crystallographic observations. HDX-MS analysis revealed areas of solvent protection changes in the MG8 domain, resulting from the binding of K8, and in the MG1 and MG5 domains of the C5-K92 complex (Figure 6), corresponding to their respective epitopes, as identified with X-ray crystallography (Figure 3 ) and confirmed by sitedirected mutagenesis analysis. Changes in solvent exposure were also observed in the $\alpha$-chain for C5-K92, providing a route to visualise the allosteric network. As similar conformational or dynamic changes occur both in solution and in the crystal structure, this suggests that the effects are ligand induced and are not the result of crystal packing interactions. SAXS analysis also suggests that K8 and $\mathrm{K} 92$ increase the flexibility of $\mathrm{C} 5$ and effects on dynamics may be a contributing factor in realising efficacy (Figure 5).

For K57, which had an $E_{\max }$ of $100 \%$ for both pathways and was not demonstrably allosteric, HDX-MS and biacore experiments with the metastable C5b suggested a putative epitope on the MG5 domain. This could support an orthosteric mechanism of action as CVF, which can form a stable C5 convertase, contacts the MG5 domain in the C5-CVF co-crystal structure (PDB accession code 3PVM). However, by SAXS, similar changes in conformation and/or dynamics to the C5-K8 and C5- 
K92 complexes were apparent and an allosteric network, including changes in the C5d domain, was observed in the C5-K92 complex by HDX-MS. These observations could support an allosteric mechanism for K57.

Importantly, we also saw a high degree of negative cooperativity between the different knob domains by SPR (Figure 2), suggesting that all the functional knob domains perturb the conformational state or dynamics of C5. K57 also showed cooperativity with other functional knob domains, suggesting providing further evidence that it stabilises a conformation of C5 that is less energetically favourable for binding of the other ligands.

Our observations with $\mathrm{K} 92$ suggest that further work may be required to elucidate the mechanism of action of another binder of the MG1 and MG5 domains, SSL7. Given that SSL7 can be a partial inhibitor (Laursen et al., 2010), even with co-binding of IgA, this precludes a steric mechanism and invites biophysical studies in solution. Additionally, another tick-derived inhibitor, Cirp-T, was also recently reported as predominantly binding to the MG4 domain, with an orthosteric mechanism of action attributed. However, we note that published data only showed an $E_{\max }$ of $<90 \%$ in AP-driven assays (Reichhardt et al., 2020), indicating that it is an allosteric C5 inhibitor for the AP, and potentially also the $\mathrm{CP}, \mathrm{C} 5$ convertase, which may merit further investigation.

In conclusion, we introduce knob domains as a new peptide modality, with unexplored therapeutic potential for the modulation of proteins and protein-protein interactions. This study is the first application of knob domain peptides and reveals an unexpectedly high incidence of allosteric modulators of complement C5, expanding its scope for complement-targeted therapies and providing important mechanistic tools for the study of C5 convertases. Knob domains can offer a range of advantages over the current macromolecular C5 inhibitors, including their use as peptide therapeutics, while grafting knob domains into the CDRH3 of well-characterised Fabs or using Fc tags could provide routes to extend half-life in vivo by attenuating renal clearance.

\section{Materials and methods}

\section{Complement proteins}

Human C5 was affinity purified using an E141A, H164A OmCl column (Macpherson et al., 2018). Briefly, human serum (TCS Biosciences, Botolph Claydon, UK) was diluted 1:1 (v/v) with phosphate buffered saline (PBS), $20 \mathrm{mM}$ ethylenediaminetetraacetic acid (EDTA), and applied to a $5 \mathrm{~mL} H \mathrm{Hi}$-Trap NHS column (GE Healthcare, Amersham UK), which contained 20 mg of E141A H164A OmCl protein, at a rate of $1 \mathrm{~mL} / \mathrm{min}$. The column was washed with $5 \times$ column volumes (CV) of PBS, C5 was then eluted using $2 \mathrm{M} \mathrm{MgCl}_{2}$ and immediately dialysed into PBS. C5b was prepared from human C5 by incubating $C 5$ with CVF, factor $B$ and factor $D$, at a 1:10 molar ratio, as previously described (Jore et al., 2016). C5a was removed using a spin column with 30 kDa cut-off (Thermo Fisher Scientific, Horsham, UK).

\section{Knob domain peptide production}

Knob domain peptides were expressed fused to the CDRH3 of the PGT-121 Fab, as previously described (Macpherson et al., 2020). Plasmid DNA for each construct was amplified using QIAGEN Plasmid Plus Giga Kits. Expi293F cultures were transfected with Expifectamine 293 Transfection kits (Invitrogen, Renfrew, UK) as per the manufacturer's instructions. The cells were cultured for 4 days and supernatants harvested by centrifugation at $4000 \mathrm{rpm}$ for $1 \mathrm{hr}$. Harvested supernatants were applied to a Hi-Trap Nickel excel columns (GE Healthcare, Amersham, UK) using an Akta pure (GE Healthcare, Amersham, UK). Cell supernatants were loaded at $2.5 \mathrm{~mL} / \mathrm{min}$, followed by a wash of $7 \times$ $\mathrm{CV}$ of PBS, $0.5 \mathrm{M} \mathrm{NaCl}$. A second wash with $7 \times \mathrm{CV}$ of buffer $\mathrm{A}(0.5 \mathrm{M} \mathrm{NaCl}, 0.02 \mathrm{M}$ Imidazole, PBS $\mathrm{pH}$ 7.3) was performed, and samples were eluted by isocratic elution with $10 \times \mathrm{CV}$ of buffer $\mathrm{B}(0.5 \mathrm{M}$ $\mathrm{NaCl}, 0.25 \mathrm{M}$ ) Imidazole, PBS ( $\mathrm{pH}$ 7.3). Post elution, the protein-containing fractions were pooled and buffer exchanged into PBS using dialysis cassettes (Thermo Fisher Scientific, Horsham, UK).

For isolation of the knob domain peptide, PGT-121 Fab-knob peptide fusion proteins were incubated with tobacco etch virus protease, at a ratio of 100:1 (w/w), for a minimum of $2 \mathrm{hr}$ at room temperature. Peptides were purified using a Waters UV-directed FractionLynx system with a Waters XBridge Protein BEH C4 OBD Prep Column (300 ̊, $5 \mu \mathrm{m}, 19 \times 100$ mm, Waters Corp., Milford, MA). An aqueous solvent of water, $0.1 \%$ trifluoroacetic acid (TFA), and an organic solvent of $100 \%$ 
$\mathrm{MeCN}$ was used. The column was run at $20 \mathrm{~mL} / \mathrm{min}$ at $40^{\circ} \mathrm{C}$ with a gradient of $5-50 \%$ organic solvent, over $11 \mathrm{~min}$. Fractions containing knob peptide were pooled and lyophilised using a Labconco Freezone freeze drier.

\section{Complement activation assays}

For the C3 and C9 ELISAs, microtiter plates (MaxiSorp; Nunc) were incubated overnight at $4^{\circ} \mathrm{C}$ with $50 \mu \mathrm{L}$ of a solution of in $75 \mathrm{mM}$ sodium carbonate $(\mathrm{pH} 9.6)$ containing either $2.5 \mu \mathrm{g} / \mathrm{mL}$ aggregated human IgG (Sigma-Aldrich, Gillingham, UK) for CP or $20 \mu \mathrm{g} / \mathrm{mL}$ zymosan (Sigma-Aldrich, Gillingham, UK) for AP. As a negative control, wells were coated with $1 \%(w / v)$ bovine serum albumin (BSA)/PBS. Microtiter plates were washed four times with $250 \mu \mathrm{L}$ of wash buffer $(50 \mathrm{mM}$ Tris- $\mathrm{HCl}), 150 \mathrm{mM} \mathrm{NaCl}$ and $0.1 \%$ Tween $20(\mathrm{pH}$ 8) between each step of the procedure. Wells were blocked using $250 \mu \mathrm{L}$ of $1 \%(\mathrm{w} / \mathrm{v})$ BSA/PBS for $2 \mathrm{hr}$ at room temperature. Normal human serum was diluted in either gelatin veronal buffer with calcium and magnesium $\left(\mathrm{GVB}^{++}: 0.1 \%\right.$ gelatin, $5 \mathrm{mM}$ Veronal buffer, $145 \mathrm{mM}$ $\mathrm{NaCl}, 0.025 \% \mathrm{NaN}_{3}, 0.15 \mathrm{mM}$ calcium chloride, $1 \mathrm{mM}$ magnesium chloride, $\mathrm{pH}$ 7.3; for $\mathrm{CP}$ ) or $\mathrm{Mg}$ ethylene glycol tetraacetic acid (Mg-EGTA) (2.5 mM veronal buffer [pH 7.3] containing $70 \mathrm{mM}$ of $\mathrm{NaCl}, 140 \mathrm{mM}$ of glucose, $0.1 \%$ gelatin, $7 \mathrm{mM}$ of $\mathrm{MgCl} 2$, and $10 \mathrm{mM}$ of EGTA; for AP). Serum was used at a concentration of $1 \%$ in $\mathrm{CP}$ or $5 \%$ in $\mathrm{AP}$ and was mixed with serially diluted concentrations of peptides (16 $\mu \mathrm{M}-15.6 \mathrm{nM}$ ) in $\mathrm{GVB}^{++}$or Mg-EGTA buffer, and preincubated on ice for $30 \mathrm{~min}$. Peptide-serum solutions were then incubated in the wells of microtiter plates for 35 min for CP assays (both $\mathrm{C} 3 \mathrm{~b}$ and $\mathrm{C} 9$ detection) or $35 \mathrm{~min}$ for $\mathrm{AP}(\mathrm{C} 3 \mathrm{~b})$ or $60 \mathrm{~min}$ for $\mathrm{AP}(\mathrm{C} 9)$, at $37^{\circ} \mathrm{C}$. Complement activation was assessed through detection of deposited complement activation factors using specific antibodies against C3b (rat anti-human C3d HM2198, Hycult, Uden, The Netherlands) and C9 (goat anti-human C9, A226, Complement Technologies Tyler, TX) at a 1:1000 dilution. Bound primary antibodies were detected with horse rdischHRP-conjugated goat anti-rat (ab97057, Abcam, Cambridge, UK) or rabbit anti-goat (P0449, Agilent Dako, Santa Clara, CA) secondary antibodies at a 1:1000 dilution. Bound HRP-conjugated antibodies were detected using TMB One solution (Eco-TEK - manufactured by Bio-TEK, Winooski, VT) with absorbance measured at 450 $\mathrm{nm}$.

For the C5b ELISA, assays were run using the CP and AP Complement functional ELISA kits (Svar Life Science, Malmö, Sweden). For sample preparation, serum was diluted as per the respective protocol for the CP and AP assays. Serial dilutions of peptides were prepared and allowed to incubate with serum for $15 \mathrm{~min}$ at room temperature prior to plating.

For the C5a ELISA, assays were run using the Complement C5a Human ELISA Kit (Invitrogen, Renfrew, UK). For sample preparation, at the end of the $37^{\circ} \mathrm{C}$ incubation of the serum/ peptide samples on the C5b ELISA plate, $50 \mu \mathrm{L}$ of the diluted, activated serum was transferred to a C5a ELISA plate containing $50 \mu \mathrm{L} /$ well of assay buffer. All subsequent experimental steps were performed as described in the protocol.

\section{Haemolysis assays}

$\mathrm{GVB}^{++}$or Mg EGTA buffers, which had been supplemented with $2.5 \%$ glucose $(\mathrm{w} / \mathrm{v})$, were used for the $C P$ and $A P$ assays, respectively. For the $A P, 150 \mu \mathrm{L}$ of rabbit erythrocytes (TCS Biosciences, Botolph Claydon, UK) were washed twice, by addition of $1 \mathrm{~mL}$ of buffer and centrifugation at $800 \times g$ for $1 \mathrm{~min}$, and finally resuspended in $500 \mu \mathrm{L}$ of buffer. For the $\mathrm{CP}, 150 \mu \mathrm{L}$ sheep erythrocytes (TCS Biosciences, Botolph Claydon, UK) were washed twice with $1 \mathrm{~mL}$ of buffer and sensitised with a 1/1000 dilution of rabbit anti-sheep red blood cell stroma antibody (S1389, Sigma Aldrich, Gillingham, UK). After a $30^{\circ} \mathrm{C} / 30$ min incubation, with shaking, the cells were rewashed and resuspended with $500 \mu \mathrm{L}$ of buffer. Serial dilutions of peptide were prepared in the respective buffers and normal human serum was added at $1 \%$ for the $C P$ and $4.5 \%$ for the AP (corresponding to $\mathrm{CH} 50$ of the serum). Also, $90 \mu \mathrm{L}$ of peptide-serum mixtures were plated into a V-bottom 96-well microtiter plate (Corning) and $10 \mu \mathrm{L}$ of erythrocytes were added. Plates were incubated for $30 \mathrm{~min}$ at $37^{\circ} \mathrm{C}$, with shaking. Finally, $50 \mu \mathrm{L}$ of buffer was added, the plates centrifuged at $800 \times 9$, and 80 $\mu \mathrm{L}$ of supernatant was transferred to an ELISA plate (Nunc) and absorbance measured at $405 \mathrm{~nm}$. 


\section{Crystallography and structure determination}

$6.1 \mathrm{mg} / \mathrm{mL} \mathrm{C5}(20 \mathrm{mM}$ Tris- $\mathrm{HCl}, 75 \mathrm{mM} \mathrm{NaCl}, \mathrm{pH} 7.35)$ was mixed at a 1:1 molar ratio with either the K8 or $\mathrm{K} 92$ peptides. Crystallisation trials were initiated by the vapor diffusion method at $18^{\circ} \mathrm{C}$ with a 1:1 mixture of mother liquor $(\mathrm{v} / \mathrm{v})$. C5-K8 crystals were grown in a mother liquor of $0.1 \mathrm{M}$ $\mathrm{N}$-(2-acetamido)iminodiacetic $\mathrm{A}, 14 \%$ ethanol $(\mathrm{v} / \mathrm{v}), \mathrm{pH}$ 6.0. For $\mathrm{C} 5-\mathrm{K} 92$ crystals, the mother liquor was $0.1 \mathrm{M}$ bicine/Trizma (pH 8.5), $10 \%(\mathrm{w} / \mathrm{v})$ polyethylene glycol $8000,20 \%(\mathrm{v} / \mathrm{v})$ ethylene glycol, 30 $\mathrm{mM}$ sodium fluoride, $30 \mathrm{mM}$ sodium bromide, and $30 \mathrm{mM}$ sodium iodide (Gorrec, 2009). Prior to flash freezing in liquid nitrogen, C5-K8 crystals were cryoprotected in mother liquor with $30 \% 2$ methyl-2,4-pentanediol (v/v). C5-K92 crystals were frozen without additional cryoprotection.

Data were collected at the Diamond Light Source (Harwell, UK), on beamline 103, at a wavelength of $0.9762 \AA$. The C5-K8 structure was solved using the automated molecular replacement pipeline Balbes (Long et al., 2008) using the apo C5 structure (PDB accession code 3CU7), minus the C345c domain. The C5-K8 complex crystallised in space group $\mathrm{P} 2{ }_{1}{ }_{2}{ }_{1} 2_{1}$ with one molecule in the asymmetric unit. A backbone model of the K8 peptide was produced using ARP-wARP (Langer et al., 2008) which informed manual model building in Coot (Emsley et alo, 2010), within the CCP4 suite (Winn et alo, 2011). The model was subjected to multiple rounds of refinement in Refmac (Murshudov et alo, 1997) and Phenix (Adams et alo, 2010). The overall geometry in the final structure of the C5-K8 complex is good, with $97.2 \%$ of residues in favoured regions of the Ramachandran plot and no outliers.

The C5-K92 complex crystallised in space group C2 with one molecule in the asymmetric unit. C5 was solved by molecular replacement with Phaser (McCoy et al,, 2007) using the $\mathrm{C} 5-\mathrm{OmCl}-\mathrm{RaCl}$ structure (PDB accession code $5 \mathrm{HCC}$ ), with $\mathrm{OmCl}$ and $\mathrm{RaCl}$ removed. Manual building of the $\mathrm{K} 92$ peptide in Coot was greatly informed by mass spectroscopy disulphide mapping experiments. The model was subjected to multiple rounds of manual rebuilding in Coot and refinement in Phenix (Adams et al., 2010). The overall geometry in the final structure of the C5-K92 complex is good, with $95.2 \%$ of residues in favoured regions of the Ramachandran plot and no outliers. Structure factors and coordinates for both C5-knob domain peptide complexes have been deposited in the PDB (PDB accession codes: 7AD6 (C5-K92 complex) and 7AD7 (C5-K8 complex)). Crystal trials were also performed with the C5-K57 and C5-K149 complexes, but the resulting crystals diffracted poorly.

\section{Disulphide mapping of K92 peptide}

A $250 \mu \mathrm{L} \mathrm{K92} \mathrm{peptide} \mathrm{at} 1 \mathrm{mg} / \mathrm{mL}$ was alkylated with addition of $18 \mu \mathrm{L}$ of 2-lodoacetamide (Thermo Fisher Scientific, Horsham, UK) at room temperature for $30 \mathrm{~min}$. Overnight dialysis into assay buffer (7.5 mM Tris- $\mathrm{HCl}, 1.5 \mathrm{mM} \mathrm{CaCl}$, $\mathrm{pH}$ 7.9) was performed using $2 \mathrm{kDa}$ slide-a-lyzer cassettes (Thermo Fisher Scientific, Horsham, UK). Chymotrypsin (sequencing grade, Roche Applied Sciences) was reconstituted to $1 \mu \mathrm{g} / \mu \mathrm{L}$ in assay buffer, and $5 \mu \mathrm{L}$ of reconstituted enzyme was added to $80 \mu \mathrm{L}$ of sample. Once mixed, the sample was incubated at $37^{\circ} \mathrm{C}$ for $1.5 \mathrm{hr}$ before being quenched with $5 \mu \mathrm{L}$ of $1 \%$ TFA. Samples were diluted 1 in 10 and $5 \mu \mathrm{L}$ was loaded onto the analytical column.

Liquid chromatography electrospray ionisation mass spectrometry was acquired using an Ultimate 3000 UHPLC system (Thermo Fisher Scientific, Horsham, UK) coupled with a Q-Exactive Plus Orbitrap (Thermo Fisher Scientific, Horsham, UK). Separations were performed using gradient elution (A: $0.1 \%$ formic acid; B: $0.1 \%$ formic acid in acetonitrile) on an Acquity UPLC BEH C18 column (130 , $1.7 \mu \mathrm{m}, 2.1 \times 150 \mathrm{~mm}$; Waters Corp., Milford, MA) with the column temperature maintained at $40^{\circ}$ C.

The following analytical gradient at $0.2 \mathrm{~mL} / \mathrm{min}$ was used: $1 \% \mathrm{~B}$ was held for $2 \mathrm{~min}, 1-36 \%$ B over $28 \mathrm{~min}, 36-50 \%$ over $5 \mathrm{~min}$, and $50-99 \%$ B over $0.5 \mathrm{~min}$. There were sequential wash steps with changes in gradient of $99 \%-1 \%$ B over $0.5 \mathrm{~min}$ (at a higher flow rate of $0.5 \mathrm{~mL} / \mathrm{min}$ ) before equilibration at $1 \% \mathrm{~B}$ for $6.5 \mathrm{~min}$ (at the original $0.2 \mathrm{~mL} / \mathrm{min}$ ).

A full MS/dd-MS2 (Top 5) scan was run in positive mode. Full MS: scan range was $200-2000 \mathrm{~m} / \mathrm{z}$ with 70,000 resolution (at $200 \mathrm{~m} / \mathrm{z}$ ) and a $3 \times 10^{6}$ AGC target (the maximum target capacity of the C-trap), 100 ms maximum Injection time. The dd-MS2: $2.0 \mathrm{~m} / \mathrm{z}$ isolation window, CID fragmentation (NCE 28) with fixed first mass of $140.0 \mathrm{~m} / \mathrm{z}$, with a 17,500 resolution (at $200 \mathrm{~m} / \mathrm{z}$ ), $1 \times 10^{5}$ AGC target, $200 \mathrm{~ms}$ maximum injection time. The source conditions of the MS were capillary voltage, $3 \mathrm{kV}$; 
S-lens RF level, 50; sheath gas flow rate, 25; auxiliary gas flow rate, 10; auxiliary gas heater temperature, $150^{\circ} \mathrm{C}$; and the MS inlet capillary was maintained at $320^{\circ} \mathrm{C}$.

Data were acquired using XcaliburTM 4.0 software (Thermo Fisher Scientific, Horsham, UK), and raw files were analysed by peptide mapping analysis using Biopharma Finder 2.0 software (Thermo Fisher Scientific, Horsham, UK) by performing a disulphide bond search with a chymotrypsin (medium specificity) digest against the K92 peptide sequence. Assignments and integrations from Biopharma Finder were filtered to include only peptides identified as containing a single disulphide bond and with an experimental mass within $|5| \mathrm{ppm}$ of the theoretical mass. Intensities for all peptides containing the same cysteines pairing were summed and percentages were obtained from the summed against total intensities.

\section{SPR multicycle kinetics}

Kinetics were measured using a Biacore 8K (GE Healthcare, Amersham, UK) with a CM5 chip, which was prepared as follows: 1-ethyl-3-(-3-dimethylaminopropyl) carbodiimide hydrochloride (EDC)/Nhydroxysuccinimide (NHS) was mixed at 1:1 ratio (flow rate, $10 \mu \mathrm{L} / \mathrm{min}$; contact time, $30 \mathrm{~s}$ ), and human $\mathrm{C} 5$ at $1 \mu \mathrm{g} / \mathrm{mL}$ in $\mathrm{pH} 4.5$ sodium acetate buffer was injected over flow cell one only (flow rate, $10 \mu \mathrm{L} / \mathrm{min}$; contact time, $60 \mathrm{~s})$. Final immobilisation levels in the range of 2000-3000 RUs were obtained to yield theoretical Rmax values of $\sim 50-60 \mathrm{RU}$. Serial dilutions of K8 and K92 knob domains, and various mutants, were prepared in HBS-EP $(0.01 \mathrm{M} \mathrm{HEPES} \mathrm{pH} \mathrm{7.4,0.15} \mathrm{M} \mathrm{NaCl,} 3 \mathrm{mM}$ EDTA, $0.005 \%$ v/v Surfactant P20) buffer and injected (flow rate, $30 \mu \mathrm{L} / \mathrm{min}$; contact time, $240 \mathrm{~s}$; dissociation time, $6000 \mathrm{~s})$. After each injection, the surface was regenerated with two sequential injections of $2 \mathrm{M} \mathrm{MgCl}_{2}$ (flow rate, $30 \mu \mathrm{L} / \mathrm{min}$; contact time, $30 \mathrm{~s}$ ). Binding to the reference surface was subtracted, and the data were fitted to a single-site binding model using Biacore evaluation software.

\section{Binding pose metadynamics}

Simulation structures were prepared using Schrodinger's Maestro Protein preparation wizard. The molecular dynamics runs were performed using the Schrodinger's default implementation of the binding pose metadynamics with the peptide chain considered in place of a ligand. Additional RMSD calculations for the peptide internal structure assessment in the last $20 \%$ of the dynamics were performed relative to the starting structures.

\section{Small-angle X-ray scattering}

Data was collected at the EMBL P12 beam line (PETRA III, DESY Hamburg, Germany; Blanchet et al., 2015). Data was collected with inline SEC mode using the Agilent 1260 Infinity II Bio-inert LC. Also, $50 \mu \mathrm{L}$ of complement component C5 at $31.6 \mu \mathrm{M}(5.96 \mathrm{mg} / \mathrm{mL})$ was injected onto a Superdex 200 Increase 5/150 column (GE Healthcare, Amersham, UK) at a flow rate of $0.35 \mathrm{~mL} / \mathrm{min}$. The mobile phase comprised $20 \mathrm{mM}$ Tris pH 7.35, $75 \mathrm{mM} \mathrm{NaCl}$, and $3 \%$ glycerol. The column elute was directly streamed to the SAXS capillary cell, and throughout the 15-min run, 900 frames of $1 \mathrm{~s}$ exposure were collected. After data reduction and radial averaging, the program CHROMIXS (Panjkovich and Svergun, 2018) was employed. Around 100 statistically similar buffer frames were selected and used for background subtraction of the sample frames from the chromatographic peak. This results in the final I(s) vs s scattering profiles, where $s=4 \pi \sin \theta / \lambda, 2 \theta$ is the scattering angle, and $\lambda=1.24 \AA$. The scattering data in the momentum transfer range $0.05<$ $\mathrm{s}<0.32 \mathrm{~nm}^{-1}$ were collected with a PILATUS $6 \mathrm{M}$ pixel detector at a distance of $3.1 \mathrm{~m}$ from the sample.

ATSAS 2.8 (Franke et alı, 2017) was employed for further data analysis and modelling. The program PRIMUS (Konarev et al., 2003) was used to perform Guinier analysis (Inl(s) versus $\mathrm{s}^{2}$ ) from which the radius of gyration, $R_{G}$, was determined. Distance probability functions, $p(r)$, were calculated using the inverse Fourier transformation method implemented in GNOM (Svergun, 1992) that provided the maximum particle dimension, $D_{\max }$. The concentration-independent molecular weight estimate, $\mathrm{MW}_{\mathrm{VC}}$, is based on the volume of correlation (Rambo and Tainer, 2013). The values are reported in Supplementary file 1, Table 3.1.

Theoretical scattering profiles were computed from X-ray coordinates using Crysol (Svergun et al., 1995), and SREFLEX (Panjkovich and Svergun, 2016) was used to refine the 
models. For this, the program partitions the structure into pseudo-domains and hierarchically employs NMA to find the domain rearrangements minimising the discrepancy $\chi^{2}$ between the SAXS curve computed from the refined model and the experimental data. Because of the absence of electron density for the $\mathrm{C} 345 \mathrm{c}$ domain in the $\mathrm{C} 5-\mathrm{K} 8$ complex structure, we included a round of restrained rigid body refinement followed by NMA to obtain an improved fit.

On the same day, MALLS data were collected with a separate SEC run under the same experimental conditions (set-up, buffer, run parameters, etc.). For this, a Wyatt Technologies miniDAWN TREOS MALLS detector coupled to an OptiLab T-Rex differential refractometer for protein concentration determination ( $\mathrm{dn} / \mathrm{dc}$ was taken as 0.185 ) was used. The MALLS system was calibrated relative to the scattering from toluene. The MWMALLS distribution of species eluting from the SEC column were determined with the Wyatt ASTRA7 software package.

The experimental SAXS data and the models derived from them were deposited to the Small Angle Scattering Biological Data Bank (SASBDB accession number SASDJA6).

\section{Hydrogen/deuterium mass spectrometry}

A $6 \mu \mathrm{M}$ of $\mathrm{C} 5$ was incubated with $10 \mu \mathrm{M}$ of peptide (K8, K92, or K57) to achieve complex during deuterium exchange conditions. Then, $4 \mu \mathrm{L}$ of $\mathrm{C} 5$ or the $\mathrm{C} 5$-peptide complex were diluted into 57 $\mu \mathrm{L}$ of $10 \mathrm{mM}$ phosphate in $\mathrm{H}_{2} \mathrm{O}\left(\mathrm{pH} \mathrm{7.0)}\right.$ or into $10 \mathrm{mM}$ phosphate in $\mathrm{D}_{2} \mathrm{O}(\mathrm{pD} 7.0)$ at $25^{\circ} \mathrm{C}$. The deuterated samples were then incubated for $0.5,2,15$, and $60 \mathrm{~min}$ at $25^{\circ} \mathrm{C}$. After the reaction, all samples were quenched by mixing at 1:1 (v/v) with a quench buffer (4 M guanidine hydrochloride, 250 $\mathrm{mM}$ Tris (2-carboxyethyl) phosphine hydrochloride, $100 \mathrm{mM}$ phosphate) at $1^{\circ} \mathrm{C}$. The final mixed solution was $\mathrm{pH}$ 2.5. The mixture was then immediately injected into the nanoAcquity HDX module (Waters Corp., Milford, MA) for peptic digest using an enzymatic online digestion column (Waters Corp., Milford, MA) in $0.2 \%$ formic acid in water at $20^{\circ} \mathrm{C}$ and with a flow rate of $100 \mu \mathrm{L} / \mathrm{min}$. All deuterated time points and undeuterated controls were carried out in triplicate with blanks run between each data point.

Peptide fragments were then trapped using an Acquity BEH C18 1.7 $\mu \mathrm{M}$ VANGUARD chilled precolumn for 3 min. Peptides were eluted into a chilled Acquity UPLC BEH C18 $1.7 \mu \mathrm{m} 1.0 \times 100$ using the following gradient: $0 \mathrm{~min}, 5 \% \mathrm{~B} ; 6 \mathrm{~min}, 35 \% \mathrm{~B} ; 7 \mathrm{~min}, 40 \% \mathrm{~B} ; 8 \mathrm{~min}, 95 \% \mathrm{~B}, 11 \mathrm{~min}, 5 \% \mathrm{~B} ; 12$ $\min , 95 \% \mathrm{~B} ; 13 \mathrm{~min}, 5 \% \mathrm{~B} ; 14 \mathrm{~min}, 95 \% \mathrm{~B}$; and $15 \mathrm{~min}, 5 \% \mathrm{~B}(\mathrm{~A}: 0.2 \% \mathrm{HCOOH}$ in $\mathrm{H} 2 \mathrm{O} ; \mathrm{B}: 0.2 \%$ $\mathrm{HCOOH}$ ) in acetonitrile. The trap and UPLC columns were both maintained at $0^{\circ} \mathrm{C}$. Peptide fragments were ionised by positive electrospray into a Synapt G2-Si mass spectrometer (Waters Corp., Milford, MA). Data acquisition was run in ToF-only mode over an $\mathrm{m} / \mathrm{z}$ range of 50-2000 Th using an MSE method (low collision energy, $4 \mathrm{~V}$; high collision energy: ramp from $18 \mathrm{~V}$ to $40 \mathrm{~V}$ ). Glu-1-Fibrinopeptide $B$ peptide was used for internal lock mass correction. To avoid significant peptide carry-over between runs, the on-line Enzymate pepsin column (Waters Corp., Milford, MA) was washed three times with pepsin wash $(0.8 \%$ formic acid, $1.5 \mathrm{M} \mathrm{Gu}-\mathrm{HCl}, 4 \% \mathrm{MeOH})$ and a blank run was performed between each sample run.

MSE data from undeuterated samples of C5 were used for sequence identification using the Waters Protein Lynx Global Server 2.5.1 (PLGS). Ion accounting files for the three control samples were combined into a peptide list imported into DynamX v3.0 software (Waters Corp., Milford, MA). The output peptides were subjected to further filtering in DynamX. Filtering parameters used were minimum and maximum peptide sequence length of 4 and 25, respectively, minimum intensity of 1000 , minimum MS/MS products of 2, minimum products per amino acid of 0.2 , and a maximum $\mathrm{MH}+$ error threshold of $10 \mathrm{ppm}$. DynamX was used to quantify the isotopic envelopes resulting from deuterium uptake for each peptide at each time point. Furthermore, all the spectra were examined and checked visually to ensure correct assignment of $\mathrm{m} / \mathrm{z}$ peaks and only peptides with a high signal to noise ratios were used for HDX-MS analysis.

Following manual filtration in DynamX, confidence intervals for differential HDX-MS $(\Delta H D X)$ measurements of individual time point were calculated using Deuteros (Lau et al., 2019) software. Only peptides which satisfied a $\triangle \mathrm{HDX}$ confidence interval of $98 \%$ were considered significant. The $\Delta \mathrm{HDX}$ was then plotted onto the C5 structure in Pymol. 


\section{Surface plasmon resonance, single-cycle kinetics}

On a Biacore 8K (GE Healthcare, Amersham, UK), human C5b was immobilised on a CM5 chip (GE Healthcare, Amersham, UK). Flow cells were activated using a standard immobilisation protocol: EDC/NHS was mixed at 1:1 ratio (flow rate, $10 \mu \mathrm{L} / \mathrm{min}$; contact time, $30 \mathrm{~s}$ ). C5b, at $1 \mu \mathrm{g} / \mathrm{mL}$, or C5b6 (Complement Technologies, Tyler, TX), at $2 \mu \mathrm{g} / \mathrm{mL}$, in $\mathrm{pH} 4.5$ sodium acetate buffer, were immobilised on flow cell two only (flow rate, $10 \mu \mathrm{L} / \mathrm{min}$; contact time, $420 \mathrm{~s}$ ). Finally, ethanolamine was applied to both flow cells (flow rate, $10 \mu \mathrm{L} / \mathrm{min}$; contact time, $420 \mathrm{~s}$ ). A final immobilisation level of 500-700 RUs was obtained for C5b and 1000-1150 RUs were obtained for C5b-6. Single-cycle kinetics were measured using a seven-point, threefold serial dilution (spanning a range of $1 \mu \mathrm{M}$ to 1.4 $\mathrm{nM}$ ) in HBS-EP buffer (GE Healthcare, Amersham, UK). A high flow rate of $40 \mu \mathrm{L} / \mathrm{min}$ was used, with a contact time of $300 \mathrm{~s}$ and a dissociation time of $2700 \mathrm{~s}$. Binding to the reference surface was subtracted, and the data were fitted to a single-site binding model using Biacore evaluation software. All sensorgrams were inspected for evidence of mass transport limitation using the flow rate-independent component of the mass transfer constant (tc).

\section{Surface plasmon resonance, cross blocking}

On a Biacore 8K (GE Healthcare, Amersham, UK), human C5 was amine coupled to a CM5 chip using the same protocol as for C5b. A final immobilisation level of approximately 1000-2000 RUs was obtained. For cross blocking, the surface was saturated with two sequential injections of a $20 \mu \mathrm{M}$ knob domain solution in HBS-EP buffer (GE Healthcare, Amersham, UK) using a flow rate of $30 \mu \mathrm{L} /$ min and contact time of $300 \mathrm{~s}$. This was immediately followed with an injection of a second knob domain peptide, again at $20 \mu \mathrm{M}$ in HBS-EP, with a flow rate of $30 \mu \mathrm{L} / \mathrm{min}$ and a contact time of 270 $\mathrm{s}$, and the dissociation phase was measured for $600 \mathrm{~s}$. Binding to the reference surface was subtracted, and sensorgrams were plotted in GraphPad Prism (GraphPad Software, San Diego, California USA, www.graphpad.com).

\section{Acknowledgements}

We thank John Cashman for his help during crystallography screening. We are grateful to the three reviewers and editor for their valuable comments that helped to improve our manuscript.

\section{Additional information}

\section{Competing interests}

Charlotte M Deane: Reviewing editor, eLife. Alex Macpherson, Zainab Ahdash, James R Birtley, Monika-Sarah ED Schulze, Ben Holmes, Vladas Oleinikovas, James Snowden, Victoria Ellis, Alastair DG Lawson: employee of UCB and may hold shares and/or stock options. Tom Eirik Mollnes: T.E.M is a Board member of Ra Pharmaceuticals, Inc. The other authors declare that no competing interests exist.

Funding

No external funding was received for this work.

Author contributions

Alex Macpherson, Conceptualization, Data curation, Formal analysis, Validation, Investigation, Visualization, Methodology, Writing - original draft, Writing - review and editing; Maisem Laabei, Data curation, Formal analysis, Investigation; Zainab Ahdash, Formal analysis, Investigation, Methodology; Melissa A Graewert, Sarah A Robinson, Ben Holmes, Vladas Oleinikovas, Per H Nilsson, James Snowden, Victoria Ellis, Tom Eirik Mollnes, Dmitri Svergun, Investigation, Methodology; James R Birtley, Monika-Sarah ED Schulze, Susan Crennell, Formal analysis, Validation, Investigation, Methodology; Charlotte M Deane, Formal analysis, Investigation, Methodology, Writing - original draft; Alastair DG Lawson, Conceptualization, Resources, Formal analysis, Supervision, Validation, Investigation, Methodology, Writing - original draft, Project administration, Writing - review and editing; Jean $\mathrm{MH}$ van den Elsen, Conceptualization, Resources, Data curation, Formal analysis, Supervision, Funding 
acquisition, Validation, Investigation, Visualization, Methodology, Writing - original draft, Project administration, Writing - review and editing

Author ORCIDs

Alex Macpherson (D) http://orcid.org/0000-0002-4508-5322

Maisem Laabei (iD) http://orcid.org/0000-0002-8425-3704

Zainab Ahdash (iD) http://orcid.org/0000-0002-4495-8689

James Snowden (iD) http://orcid.org/0000-0003-4855-7329

Jean $\mathrm{MH}$ van den Elsen (iD) https://orcid.org/0000-0002-0367-1956

Decision letter and Author response

Decision letter https://doi.org/10.7554/eLife.63586.sa1

Author response https://doi.org/10.7554/eLife.63586.sa2

\section{Additional files}

Supplementary files

- Supplementary file 1. Section 1. Functional analysis. Table 1.1. Classical pathway C5b deposition ELISA; Table 1.2. Alternative pathway C5b deposition ELISA; Table 1.3. Inhibition of classical pathway-mediated C5a release; Table 1.4. Inhibition of alternative pathway-mediated C5a release; Table 1.5. Inhibition of classical pathway-mediated C9 deposition; Table 1.6. Inhibition of alternative pathway-mediated C9 deposition; Table 1.7. Inhibition of classical pathway haemolysis; Table 1.8. Inhibition of alternative pathway haemolysis. Section 2. Structural analysis. Table 2.1. Data collection and refinement statistics (molecular replacement); Table 2.2. Hydrogen bond interactions between K8 and C5; Table 2.3. Ionic interactions between K8 and C5; Table 2.4. Disulphide mapping of the K92 peptide; Table 2.5. Hydrogen bond interactions between $\mathrm{K} 92$ and C5; Table 2.6. Validation of molecular interactions by peptide mutagenesis analysis; Table 2.7. Individual, total, and average hydrogen bond persistence in a binding pose metadynamics simulation of the K8-C5 complex; Table 2.8. Individual, total, and average hydrogen bond persistence in a binding pose metadynamics simulation of the K92-C5 complex. Section 3. Solution structure analysis. Table 3.1. SAXS Summary data; Table 3.2. $\triangle$ HDX summary data. Section 4. Additional functional analyses. Table 4.1. SPR single-cycle kinetics of knob domains binding to human C5b; Table 4.2. SPR single-cycle kinetics of knob domains binding to human C5b-6.

- Transparent reporting form

Data availability

Structural datasets presented in this study have been made publicly available in the Protein Data Bank (PDB) and Small Angle Scattering Biological Data Bank (SASBDB).

The following datasets were generated:

\begin{tabular}{|c|c|c|c|c|}
\hline Author(s) & Year & Dataset title & Dataset URL & $\begin{array}{l}\text { Database and } \\
\text { Identifier }\end{array}$ \\
\hline $\begin{array}{l}\text { Macpherson A, } \\
\text { Elsen JM }\end{array}$ & 2021 & Crystal structure C5-K8 complex & $\begin{array}{l}\text { https://www.rcsb.org/ } \\
\text { structure/7AD7 }\end{array}$ & $\begin{array}{l}\text { RCSB Protein Data } \\
\text { Bank, 7AD7 }\end{array}$ \\
\hline $\begin{array}{l}\text { Macpherson A, } \\
\text { Elsen JM }\end{array}$ & 2021 & $\begin{array}{l}\text { Crystal structure of C5-K92 } \\
\text { complex }\end{array}$ & $\begin{array}{l}\text { https://www.rcsb.org/ } \\
\text { structure/7AD6 }\end{array}$ & $\begin{array}{l}\text { RCSB Protein Data } \\
\text { Bank, 7AD6 }\end{array}$ \\
\hline $\begin{array}{l}\text { Macpherson A, } \\
\text { Elsen JM, Graewert } \\
\text { MA, Svergun D }\end{array}$ & 2020 & $\begin{array}{l}\text { SAXS data and models of } \mathrm{C} 5 \text { - } \\
\text { bovine knob domain peptides }\end{array}$ & $\begin{array}{l}\text { https://www.sasbdb.org/ } \\
\text { data/SASDJA6/ }\end{array}$ & $\begin{array}{l}\text { Small Angle } \\
\text { Scattering Biological } \\
\text { Data Bank, SASDJA6 }\end{array}$ \\
\hline
\end{tabular}

\section{References}

Adams PD, Afonine PV, Bunkóczi G, Chen VB, Davis IW, Echols N, Headd JJ, Hung LW, Kapral GJ, GrosseKunstleve RW, McCoy AJ, Moriarty NW, Oeffner R, Read RJ, Richardson DC, Richardson JS, Terwilliger TC,

Zwart PH. 2010. PHENIX: a comprehensive Python-based system for macromolecular structure solution. Acta 
Crystallographica Section D Biological Crystallography 66:213-221. DOI: https://doi.org/10.1107/

S0907444909052925, PMID: 20124702

Albazli K, Kaminski HJ, Howard JF. 2020. Complement inhibitor therapy for myasthenia gravis. Frontiers in Immunology 11:917. DOI: https://doi.org/10.3389/fimmu.2020.00917, PMID: 32582144

Aleshin AE, DiScipio RG, Stec B, Liddington RC. 2012. Crystal structure of C5b-6 suggests structural basis for priming assembly of the membrane attack complex. Journal of Biological Chemistry 287:19642-19652. DOI: https://doi.org/10.1074/jbc.M112.361121

Bestebroer J, Aerts PC, Rooijakkers SH, Pandey MK, Köhl J, van Strijp JA, de Haas CJ. 2010. Functional basis for complement evasion by staphylococcal superantigen-like 7. Cellular Microbiology 12:1506-1516. DOI: https:// doi.org/10.1111/j.1462-5822.2010.01486.x, PMID: 20545943

Biesecker G, Dihel L, Enney K, Bendele RA. 1999. Derivation of RNA aptamer inhibitors of human complement C5. Immunopharmacology 42:219-230. DOI: https://doi.org/10.1016/S0162-3109(99)00020-X, PMID: 10408383

Blanchet CE, Spilotros A, Schwemmer F, Graewert MA, Kikhney A, Jeffries CM, Franke D, Mark D, Zengerle R, Cipriani F, Fiedler S, Roessle M, Svergun DI. 2015. Versatile sample environments and automation for biological solution X-ray scattering experiments at the P12 beamline (PETRA III, DESY). Journal of Applied Crystallography 48:431-443. DOI: https://doi.org/10.1107/S160057671500254X, PMID: 25844078

Borodovsky A, Yucius K, Sprague A, Banda NK, Holers VM, Vaishnaw A, Maier M, Kallanthottathil R, Charisse K, Kuchimanchi S, Manoharan M, Salant DJ, Fitzgerald K, Meyers R, Sorensen B. 2014. Aln-CC5, an investigational RNAi therapeutic targeting C5 for complement inhibition. Blood 124:1606-. DOI: https://doi.org/10.1182/ blood.V124.21.1606.1606

Clark AJ, Tiwary P, Borrelli K, Feng S, Miller EB, Abel R, Friesner RA, Berne BJ. 2016. Prediction of ProteinLigand binding poses via a combination of induced fit docking and metadynamics simulations. Journal of Chemical Theory and Computation 12:2990-2998. DOI: https://doi.org/10.1021/acs.jctc.6b00201, PMID: 27145262

DiScipio RG. 1981. The conversion of human complement component C5 into fragment C5b by the alternativepathway C5 convertase. Biochemical Journal 199:497-504. DOI: https://doi.org/10.1042/bj1990497

Dunbar J, Krawczyk K, Leem J, Baker T, Fuchs A, Georges G, Shi J, Deane CM. 2014. SAbDab: the structura antibody database. Nucleic Acids Research 42:D1140-D1146. DOI: https://doi.org/10.1093/nar/gkt1043

Emsley P, Lohkamp B, Scott WG, Cowtan K. 2010. Features and development of coot. Acta Crystallographica. Section D, Biological Crystallography 66:486-501. DOI: https://doi.org/10.1107/S0907444910007493, PMID: 20383002

Flyak Al, Ruiz S, Colbert MD, Luong T, Crowe JE, Bailey JR, Bjorkman PJ. 2018. HCV broadly neutralizing antibodies use a $\mathrm{CDRH} 3$ disulfide motif to recognize an E2 glycoprotein site that can be targeted for vaccine design. Cell Host \& Microbe 24:703-716. DOI: https://doi.org/10.1016/j.chom.2018.10.009, PMID: 30439340

Franke D, Petoukhov MV, Konarev PV, Panjkovich A, Tuukkanen A, Mertens HDT, Kikhney AG, Hajizadeh NR, Franklin JM, Jeffries CM, Svergun DI. 2017. ATSAS 2.8: a comprehensive data analysis suite for small-angle scattering from macromolecular solutions. Journal of Applied Crystallography 50:1212-1225. DOI: https://doi org/10.1107/S1600576717007786, PMID: 28808438

Fredslund F, Laursen NS, Roversi P, Jenner L, Oliveira CL, Pedersen JS, Nunn MA, Lea SM, Discipio R, SottrupJensen L, Andersen GR. 2008. Structure of and influence of a tick complement inhibitor on human complement component 5. Nature Immunology 9:753-760. DOI: https://doi.org/10.1038/ni.1625, PMID: 18536718

Fukuzawa T, Sampei Z, Haraya K, Ruike Y, Shida-Kawazoe M, Shimizu Y, Gan SW, Irie M, Tsuboi Y, Tai H, Sakiyama T, Sakamoto A, Ishii S, Maeda A, Iwayanagi Y, Shibahara N, Shibuya M, Nakamura G, Nambu T, Hayasaka A, et al. 2017. Long lasting neutralization of C5 by SKY59, a novel recycling antibody, is a potential therapy for complement-mediated diseases. Scientific Reports 7:1080. DOI: https://doi.org/10.1038/s41598017-01087-7, PMID: 28439081

Fusani L, Palmer DS, Somers DO, Wall ID. 2020. Exploring ligand stability in protein crystal structures using binding pose metadynamics. Journal of Chemical Information and Modeling 60:1528-1539. DOI: https://doi. org/10.1021/acs.jcim.9b00843, PMID: 31910338

Gorrec F. 2009. The MORPHEUS protein crystallization screen. Journal of Applied Crystallography 42:10351042. DOI: https://doi.org/10.1107/S0021889809042022, PMID: 22477774

Gotze O, Muiller-Eberhard HJ. 1970. Lysis of erythrocytes by complement in the absence of antibody. Journal of Experimental Medicine 132:898-915. DOI: https://doi.org/10.1084/jem.132.5.898

Govaert J, Pellis M, Deschacht N, Vincke C, Conrath K, Muyldermans S, Saerens D. 2012. Dual beneficial effect of interloop disulfide bond for single domain antibody fragments*. Journal of Biological Chemistry 287:19701979. DOI: https://doi.org/10.1074/jbc.M111.242818

Hadders MA, Bubeck D, Roversi P, Hakobyan S, Forneris F, Morgan BP, Pangburn MK, Llorca O, Lea SM, Gros P. 2012. Assembly and regulation of the membrane attack complex based on structures of C5b6 and sC5b9. Cell Reports 1:200-207. DOI: https://doi.org/10.1016/j.celrep.2012.02.003, PMID: 22832194

Haselbach D, Schrader J, Lambrecht F, Henneberg F, Chari A, Stark H. 2017. Long-range allosteric regulation of the human 26S proteasome by 20S proteasome-targeting Cancer drugs. Nature Communications 8:15578. DOI: https://doi.org/10.1038/ncomms15578, PMID: 28541292

Holm L. 2020. DALI and the persistence of protein shape. Protein Science 29:128-140. DOI: https://doi.org/10. 1002/pro.3749, PMID: 31606894

Hutchinson JM, Mesa KA, Alexander DL, Yu B, O’Rourke SM, Limoli KL, Wrin T, Deeks SG, Berman PW. 2019. Unusual cysteine content in V1 region of gp120 from an elite suppressor that produces broadly neutralizing 
antibodies. Frontiers in Immunology 10:1021. DOI: https://doi.org/10.3389/fimmu.2019.01021, PMID: 31156622

Jendza K, Kato M, Salcius M, Srinivas H, De Erkenez A, Nguyen A, McLaughlin D, Be C, Wiesmann C, Murphy J, Bolduc P, Mogi M, Duca J, Namil A, Capparelli M, Darsigny V, Meredith E, Tichkule R, Ferrara L, Heyder J, et al. 2019. A small-molecule inhibitor of C5 complement protein. Nature Chemical Biology 15:666-668. DOI: https://doi.org/10.1038/s41589-019-0303-9, PMID: 31209353

Jore MM, Johnson S, Sheppard D, Barber NM, Li YI, Nunn MA, Elmlund H, Lea SM. 2016. Structural basis for therapeutic inhibition of complement C5. Nature Structural \& Molecular Biology 23:378-386. DOI: https://doi. org/10.1038/nsmb.3196, PMID: 27018802

Jubb H. 2015. Arpeggio: An interatomic interaction calculation web server. ARPEGGIO. 1. http://structure.bioc. cam.ac.uk/arpeggio

Klein MT, Vinson PN, Niswender CM. 2013. Approaches for probing allosteric interactions at 7 transmembrane spanning receptors. Progress in Molecular Biology and Translational Science 115:1-59. DOI: https://doi.org/10. 1016/B978-0-12-394587-7.00001-4, PMID: 23415091

Konarev PV, Volkov VV, Sokolova AV, Koch MHJ, Svergun DI. 2003. PRIMUS : a Windows PC-based system for small-angle scattering data analysis . Journal of Applied Crystallography 36:1277-1282. DOI: https://doi.org/ 10.1107/S0021889803012779

Krissinel E, Henrick K. 2007. Inference of macromolecular assemblies from crystalline state. Journal of Molecular Biology 372:774-797. DOI: https://doi.org/10.1016/j.jmb.2007.05.022, PMID: 17681537

Lachmann PJ, Thompson RA. 1970. Reactive lysis: the complement-mediated lysis of unsensitized cells. II. the characterization of activated reactor as $\mathrm{C} 56$ and the participation of C8 and C9. The Journal of Experimental Medicine 131:643-657. DOI: https://doi.org/10.1084/jem.131.4.643, PMID: 4193935

Langer G, Cohen SX, Lamzin VS, Perrakis A. 2008. Automated macromolecular model building for X-ray crystallography using ARP/wARP version 7. Nature Protocols 3:1171-1179. DOI: https://doi.org/10.1038/nprot. 2008.91, PMID: 18600222

Lau AMC, Ahdash Z, Martens C, Politis A. 2019. Deuteros: software for rapid analysis and visualization of data from differential hydrogen deuterium exchange-mass spectrometry. Bioinformatics 35:3171-3173. DOI: https:// doi.org/10.1093/bioinformatics/btz022, PMID: 30649183

Lau JL, Dunn MK. 2018. Therapeutic peptides: historical perspectives, current development trends, and future directions. Bioorganic \& Medicinal Chemistry 26:2700-2707. DOI: https://doi.org/10.1016/j.bmc.2017.06.052, PMID: 28720325

Laursen NS, Gordon N, Hermans S, Lorenz N, Jackson N, Wines B, Spillner E, Christensen JB, Jensen M, Fredslund F, Bjerre M, Sottrup-Jensen L, Fraser JD, Andersen GR. 2010. Structural basis for inhibition of complement C5 by the SSL7 protein from Staphylococcus aureus. PNAS 107:3681-3686. DOI: https://doi.org/ 10.1073/pnas.0910565107, PMID: 20133685

Laursen NS, Andersen KR, Braren I, Spillner E, Sottrup-Jensen L, Andersen GR. 2011. Substrate recognition by complement convertases revealed in the C5-cobra venom factor complex. The EMBO Journal 30:606-616. DOI: https://doi.org/10.1038/emboj.2010.341, PMID: 21217642

Lee AC-L, Harris JL, Khanna KK, Hong J-H. 2019. A comprehensive review on current advances in peptide drug development and design. International Journal of Molecular Sciences 20:2383. DOI: https://doi.org/10.3390/ ijms20102383

Long F, Vagin AA, Young P, Murshudov GN. 2008. BALBES: a molecular-replacement pipeline. Acta Crystallographica. Section D, Biological Crystallography 64:125-132. DOI: https://doi.org/10.1107/ S0907444907050172, PMID: 18094476

Macpherson A, Liu X, Dedi N, Kennedy J, Carrington B, Durrant O, Heywood S, van den Elsen J, Lawson ADG. 2018. The rational design of affinity-attenuated $\mathrm{OmCl}$ for the purification of complement $\mathrm{C} 5$. Journal of Biological Chemistry 293:14112-14121. DOI: https://doi.org/10.1074/jbc.RA118.004043

Macpherson A, Scott-Tucker A, Spiliotopoulos A, Simpson C, Staniforth J, Hold A, Snowden J, Manning L, van den Elsen J, Lawson ADG. 2020. Isolation of antigen-specific, disulphide-rich knob domain peptides from bovine antibodies. PLOS Biology 18:e3000821. DOI: https://doi.org/10.1371/journal.pbio.3000821, PMID: 32 886672

Malde AK, Hill TA, lyer A, Fairlie DP. 2019. Crystal structures of Protein-Bound cyclic peptides. Chemical Reviews 119:9861-9914. DOI: https://doi.org/10.1021/acs.chemrev.8b00807, PMID: 31046237

McCoy AJ, Grosse-Kunstleve RW, Adams PD, Winn MD, Storoni LC, Read RJ. 2007. Phaser crystallographic software. Journal of Applied Crystallography 40:658-674. DOI: https://doi.org/10.1107/S0021889807021206, PMID: 19461840

McNamara LA, Topaz N, Wang X, Hariri S, Fox L, MacNeil JR. 2017. High risk for invasive meningococcal disease among patients receiving eculizumab (Soliris) Despite receipt of meningococcal vaccine. MMWR. Morbidity and Mortality Weekly Report 66:734-737. DOI: https://doi.org/10.15585/mmwr.mm6627e1, PMID: 28704351

Murshudov GN, Vagin AA, Dodson EJ. 1997. Refinement of macromolecular structures by the maximumlikelihood method. Acta Crystallographica Section D Biological Crystallography 53:240-255. DOI: https://doi. org/10.1107/S0907444996012255, PMID: 15299926

Nürnberger J, Philipp T, Witzke O, Saez AO, Vester U, Baba HA, Kribben A, Zimmerhackl LB, Janecke AR, Nagel M, Kirschfink M. 2009. Eculizumab for atypical Hemolytic-Uremic Syndrome. New England Journal of Medicine 360:542-544. DOI: https://doi.org/10.1056/NEJMc0808527 
Panjkovich A, Svergun DI. 2016. Deciphering conformational transitions of proteins by small angle X-ray scattering and normal mode analysis. Physical Chemistry Chemical Physics 18:5707-5719. DOI: https://doi.org/ 10.1039/C5CP04540A, PMID: 26611321

Panjkovich A, Svergun DI. 2018. CHROMIXS: automatic and interactive analysis of chromatography-coupled small-angle X-ray scattering data. Bioinformatics 34:1944-1946. DOI: https://doi.org/10.1093/bioinformatics/ btx846, PMID: 29300836

Pettersen EF, Goddard TD, Huang CC, Couch GS, Greenblatt DM, Meng EC, Ferrin TE. 2004. UCSF chimera-a visualization system for exploratory research and analysis. Journal of Computational Chemistry 25:1605-1612. DOI: https://doi.org/10.1002/jcc.20084, PMID: 15264254

Ramaraj T, Angel T, Dratz EA, Jesaitis AJ, Mumey B. 2012. Antigen-antibody interface properties: Composition, residue interactions, and features of 53 non-redundant structures. Biochimica Et Biophysica Acta (BBA) Proteins and Proteomics 1824:520-532. DOl: https://doi.org/10.1016/j.bbapap.2011.12.007

Rambo RP, Tainer JA. 2013. Accurate assessment of mass, models and resolution by small-angle scattering. Nature 496:477-481. DOI: https://doi.org/10.1038/nature12070, PMID: 23619693

Reichhardt MP, Johnson S, Tang T, Morgan T, Tebeka N, Popitsch N, Deme JC, Jore MM, Lea SM. 2020. An inhibitor of complement C5 provides structural insights into activation. PNAS 117:362-370. DOI: https://doi. org/10.1073/pnas.1909973116, PMID: 31871188

Ricardo A, Arata M, DeMarco SJ, Dhamnaskar K, Hammer R, Josephson K, Seyb K, Tobe S, Wang Z, Zheng H, Treco D. 2014. Development of RA101348, a potent cyclic peptide inhibitor of C5 for Complement-Mediated diseases. Blood 124:2936. DOI: https://doi.org/10.1182/blood.V124.21.2936.2936

Romay-Penabad Z, Carrera Marin AL, Willis R, Weston-Davies W, Machin S, Cohen H, Brasier A, Gonzalez EB. 2014. Complement C5-inhibitor rEV576 (coversin) ameliorates in-vivo effects of antiphospholipid antibodies. Lupus 23:1324-1326. DOI: https://doi.org/10.1177/0961203314546022, PMID: 25228739

Rother RP, Rollins SA, Mojcik CF, Brodsky RA, Bell L. 2007. Discovery and development of the complement inhibitor eculizumab for the treatment of paroxysmal nocturnal hemoglobinuria. Nature Biotechnology 25 1256-1264. DOl: https://doi.org/10.1038/nbt1344, PMID: 17989688

Schatz-Jakobsen JA, Zhang Y, Johnson K, Neill A, Sheridan D, Andersen GR. 2016. Structural basis for Eculizumab-Mediated inhibition of the complement terminal pathway. The Journal of Immunology 197:337344. DOI: https://doi.org/10.4049/jimmunol.1600280, PMID: 27194791

Sjöholm AG. 1975. Complement components in normal serum and plasma quantitated by electroimmunoassay. Scandinavian Journal of Immunology 4:25-30. DOI: https://doi.org/10.1111/j.1365-3083.1975.tb02596.x, PMID: 49076

Smith K, Pace A, Ortiz S, Kazani S, Rottinghaus S. 2020. A phase 3 Open-label, randomized, controlled study to evaluate the efficacy and safety of intravenously administered ravulizumab compared with best supportive care in patients with COVID-19 severe pneumonia, acute lung injury, or acute respiratory distress syndrome: a structured summary of a study protocol for a randomised controlled trial. Trials 21:639. DOI: https://doi.org/ 10.1186/s13063-020-04548-z, PMID: 32660611

Sok D, Le KM, Vadnais M, Saye-Francisco KL, Jardine JG, Torres JL, Berndsen ZT, Kong L, Stanfield R, Ruiz J, Ramos A, Liang CH, Chen PL, Criscitiello MF, Mwangi W, Wilson IA, Ward AB, Smider VV, Burton DR. 2017. Rapid elicitation of broadly neutralizing antibodies to HIV by immunization in cows. Nature 548:108-111. DOI: https://doi.org/10.1038/nature23301, PMID: 28726771

Stanfield RL, Berndsen ZT, Huang R, Sok D, Warner G, Torres JL, Burton DR, Ward AB, Wilson IA, Smider WV. 2020. Structural basis of broad HIV neutralization by a vaccine-induced cow antibody. Science Advances 6: eaba0468. DOI: https://doi.org/10.1126/sciadv.aba0468

Svergun DI. 1992. Determination of the regularization parameter in indirect-transform methods using perceptual criteria. Journal of Applied Crystallography 25:495-503. DOI: https://doi.org/10.1107/S0021889892001663

Svergun D, Barberato C, Koch MHJ. 1995. CRYSOL - a Program to Evaluate X-ray Solution Scattering of Biological Macromolecules from Atomic Coordinates . Journal of Applied Crystallography 28:768-773. DOI: https://doi.org/10.1107/S0021889895007047

Takata Y, Kinoshita T, Kozono H, Takeda J, Tanaka E, Hong K, Inoue K. 1987. Covalent association of C3b with C4b within C5 convertase of the classical complement pathway. Journal of Experimental Medicine 165:14941507. DOI: https://doi.org/10.1084/jem.165.6.1494

Vogel CW, Müller-Eberhard HJ. 1982. The cobra venom factor-dependent C3 convertase of human complement a kinetic and thermodynamic analysis of a protease acting on its natural high molecular weight substrate. Journal of Biological Chemistry 257:8292-8299. DOI: https://doi.org/10.1016/S0021-9258(18)34330-8

Wilkinson T, Dixon R, Page C, Carroll M, Griffiths G, Ho LP, De Soyza A, Felton T, Lewis KE, Phekoo K, Chalmers JD, Gordon A, McGarvey L, Doherty J, Read RC, Shankar-Hari M, Martinez-Alier N, O'Kelly M, Duncan G, Walles R, et al. 2020. ACCORD: a multicentre, seamless, phase 2 adaptive randomisation platform study to assess the efficacy and safety of multiple candidate agents for the treatment of COVID-19 in hospitalised patients: a structured summary of a study protocol for a randomised controlled trial. Trials 21:691. DOI: https:// doi.org/10.1186/s13063-020-04584-9, PMID: 32736596

Winn MD, Ballard CC, Cowtan KD, Dodson EJ, Emsley P, Evans PR, Keegan RM, Krissinel EB, Leslie AG, McCoy A, McNicholas SJ, Murshudov GN, Pannu NS, Potterton EA, Powell HR, Read RJ, Vagin A, Wilson KS. 2011. Overview of the CCP4 suite and current developments. Acta Crystallographica. Section D, Biological Crystallography 67:235-242. DOI: https://doi.org/10.1107/S0907444910045749, PMID: 21460441 
Wong WK, Robinson SA, Bujotzek A, Georges G, Lewis AP, Shi J, Snowden J, Taddese B, Deane CM. 2020. AbLigity: identifying sequence-dissimilar antibodies that bind to the same epitope. bioRxiv. DOI: https://doi.org/ 10.1101/2020.03.24.004051

Zelek WM, Cole J, Ponsford MJ, Harrison RA, Schroeder BE, Webb N, Jolles S, Fegan C, Morgan M, Wise MP, Morgan BP. 2020. Complement inhibition with the C5 blocker LFG316 in severe COVID-19. American Journal of Respiratory and Critical Care Medicine 202:1304-1308. DOI: https://doi.org/10.1164/rccm.202007-2778LE, PMID: 32897730 